Search Channels of Workers and Firms over the Business Cycle

Sevak Alaverdyan 


\title{
Search Channels of Workers and Firms over the Business Cycle
}

\author{
Sevak Alaverdyan*
}

\begin{abstract}
On the one hand, in expansions it is relatively easier for workers to find jobs, so they rely less strongly on their social networks, which means that hiring through referrals should be less frequent in expansions. On the other hand, firms have difficulties to fill their open positions in expansions and rely more strongly on their social networks, which means that referral hiring may be dominating in expansions. Empirical analysis of the IAB Job Vacancy Survey data of the years from 2000 to 2013 and GSOEP data from 2000 to 2014 show that in the long run there is a positive correlation between the GDP and the proportion of workers hired through their social networks. In order to explain the effect of the productivity change on the search and matching strategies of firms and workers, this paper presents a search and matching model with several search channels. The firm chooses advertisement effort through formal search channels to maximize the asset value of an open vacancy. The workers choose their search intensity through formal channels to maximize the asset value of being unemployed. Calibration results of the model show that during expansions formal advertisement is not gainful for the firms because of competition. As a result, the firms advertise less, so the proportion of referral hiring should increase. While when the productivity increases, employment becomes more gainful, so the workers exert more effort in search through formal channels. As a result, the proportion of referral hiring should decrease. Both the estimation and the calibration results indicate that the firm-side effect dominates.
\end{abstract}

Keywords: social contacts, referrals, search effort, advertisement effort

JEL Classification: J21, J46, J63, J64

*Bielefeld Graduate School of Economics and Business, Bielefeld University, 33615 Bielefeld, Germany 


\section{Introduction}

This study investigates the search channels of workers and firms over the business cycle. In particular, how the firms and the workers change the intensity of job advertisement and the job search through different search channels during expansions or recessions. Let us observe the case of expansion. During expansions when there are many vacancies and few unemployed workers it is relatively easier for workers to find jobs, so we would expect the workers to rely less strongly on their social networks. While the firms have difficulties to fill their open positions in expansions and rely more strongly on their social networks, which means that referral hiring may be dominating in expansions. As a result, there are two counteracting effects of expansion on the proportion of referral hiring. The main objective of this paper is to find out which of the effects dominates.

Empirical analysis are conducted using the data from the German Socio-Economic Panel (SOEP) over the period 2000-2014 and the data from the IAB Job Vacancy Survey over the period 2000-2013. Further, this study uses the data on the annual GDPs of 16 German federal states provided by the Federal Statistical Office of Germany. Using the two-step estimation procedure suggested by Solon et al. (1994) we show that in the long run there is a positive correlation between the GDP and the proportion of workers hired through their social networks.

In order to explain the effect of the productivity change on the search and matching strategies of firms and workers, this paper presents a search and matching model with two search channels. In the model the workers and the firms are matched either through referrals, or through formal search channels. The firm chooses advertisement effort through formal search channels to maximize the asset value of an open vacancy. The workers choose their search intensity through formal channels to maximize the asset value of being unemployed. The wages are determined using the Nash bargaining rule, where an individual firm and worker do not influence the behavior in the rest of the labour market.

Calibration results of the model show that during expansions unemployment rate is decreasing, vacancy rate and the wages are increasing. As a result, employment becomes more gainful for the workers, and they increase the job search effort through formal channels. This behaviour of the workers reduces the proportion of referral hiring. While the firms react differently. On the one hand the productivity increases, so the advertisement of the vacancy through formal channels should become more gainful for the firms. On the other hand, there are less unemployed workers available per vacancy issued, and the wages are higher during expansions. Thus, the advertisement of the vacancy through formal channels should become less gainful for the firms. According to the calibration results advertisement effort of the firms through formal channels decreases during expansion, which means that the negative effect on the job advertisement dominates. Since the advertisement effort of the firms in the formal search channels decreases, intuitively, we would expect that the fraction of workers hired through referrals should increase. Calibrations show that the proportion of workers hired through referrals increases during expansions. Thus the negative effect of the advertisement effort decrease on the fraction dominates the positive effect of the search effort increase. Both the estimation and the calibration results indicate that the firm-side effect dominates.

There is a large literature about the job search methods used by workers and recruitment 
methods used by the firms. One of the earlier studies by Granovetter (1974) emphasizes the importance of the social contacts when observing search channels of the firms and workers. In the literature informal search methods of firms and workers include the following search channels: search through relatives, friends, acquaintances, referrals from other employees and etc. Formal search methods include search through newspaper advertisements and advertisements in the internet, search through the state and private employment agencies, school and college placement services and etc.

Different theoretical and empirical studies were conducted to show the effect of search methods of firms and workers on the labour market outcomes. Particularly, there is a strand of literature which study the effect of using referrals on wages and the probability of being hired. Montgomery (1991), Kugler (2003), Dustmann et al. (2011) and Galenianos (2013) find positive wage effect of using referrals. While Pistaferri (1999), Bentolila et al. (2010) and Zaharieva (2018) find the effect to be negative.

Montgomery (1991) finds that high ability workers will refer to an own type high ability workers based on the fact that social contacts tend to occur among workers with similar characteristics. Moreover, a worker will refer only well-qualified applicants, since his reputation is at stake. Thus the employer tries to mitigate the adverse-selection problem and the workers hired through referrals are paid higher wages. According to Kugler (2003) referees exert peer pressure on the referred workers, which enables the employer to reduce monitoring cost, and to pay lower efficiency wages to the workers hired through referrals. So the workers with relatively more contacts are matched to the jobs with higher wages. While Dustmann et al. (2011) and Galenianos (2013) assume that the the worker's match-specific productivity is less uncertain when using informal search methods compared to formal search methods. As a result both authors find that the match quality is better in case of hiring through referrals compared to the hiring through formal search channels. As a result, the workers hired through informal search methods initially get higher wages. Whereas Bentolila et al. (2010) and Zaharieva (2018) argue that referrals are more likely to cause a mismatch between worker's most productive and actual occupation. Thus the use of informal methods by the workers leads to lower quality matches between workers and firms and results in a wage penalty.

While these studies observe the effect of using referrals on the labour market outcomes, this study rather aims to find the effect of labour market conditions on the relative frequency of using referrals. In this sense, the present study is closely related to the study by Galeotti and Merlino (2003). The author finds that the use of networks and their efficiency in matching workers to jobs depends on the labor market conditions. They assume that the workers invest in their networks to keep the network active. Further, incentives in networking relate to labour market conditions, in particular, to the separation rate. When the separation rate is low, the risk of becoming unemployed is low, so is the investment of workers in their networks. When the separation rate is high, then the workers connected to a job seeker are more likely searching for job themselves, moreover, they have more contacts who they can pass the information about a vacancy. As a result, the investment in networks is less gainful, and the workers' investment in networks is low. The workers' investment in networks is high, when the separation rates are moderate. Thus, the relation between the job separation rate and the probability of a worker to find a job through 
referrals is inverse U-shaped.

Another paper by Shimer (2004) finds that when the job search cost is low, the response of the workers' search intensity to labour market condition may be acyclical. The intuition is that during expansions even low job search effort may be enough for the worker to find a job. He finds that when the labour market conditions are weak, the workers who have high probability to get hired, increase their search intensity, while others get discouraged and reduce their search intensity. Unlike Shimer (2004), our model predicts that the search intensity of workers is procyclical. This result is inline with the findings of Pissarides (2000).

The study proceeds as follows: section 2 describes the data used, discusses the empirical approach and estimation results; section 3 explains the search and matching model with several search channels, where the firms and the workers choose the intensity of advertisement and job search respectively; section 4 presents the results from the calibration of the model; section 5 concludes.

\section{Empirical Analysis}

\subsection{Data}

In this section we empirically estimate the effect of the productivity change on the search channels of the workers and the firms. Particularly, we check if the change of the GDP has significant effect on the proportion of the referral hiring, and if yes, whether the effect is positive of negative.

This subsection describes the two datasets used for the empirical analysis. This study uses data from the German Socio-Economic Panel (SOEP), and the IAB Job Vacancy Survey of the Institute for Employment Research (IAB JVS). The German Socio-Economic Panel is a longitudinal study of households and individuals, which annually covers about 11,000 households, and 30,000 individuals. The surveyed individuals are asked a wide range of questions regarding personal characteristics and employment data. In addition, currently employed respondents are asked how they found their current job, the possible answers being, through federal employment office, an advertisement in the internet or newspaper, a job-center (ARGE) and a private recruitment agency, other, and through relatives and friends. The observations where the workers found the job through relatives and friends are treated to be caused by referral hiring. The rest of the search channels are treated as a formal search channels in the analysis. Our sample includes 19148 observations on employed individuals from SOEP 2000-2014.

Whereas, IAB JVS is an annual cross-sectional survey of firms, which is representative for the German firms. The sample of the firms is drawn yearly from all firm size categories, all the industries and regions of Germany. Among the wide range of questions regarding the characteristics of the firms, the human resource managers or managing directors answer to questions about the most recent recruitment case. In particular, they answer about the recruitment channel which led to hiring of the last hired employee. In this study the recruitment channels are classified into the formal channels and referrals as follows. The employee is hired through referrals when the recruitment takes place via own employees/personal contacts, or the through internal job advertisement. The rest of the recruitment channels are included into the formal channels category. The formal recruitment channels include recruitment through private placement service, 
Federal Employment Agency, advertisements in newspapers and magazines, posting the vacancy to internet website, choosing from unsolicited applications/pool of applicants and etc. During the survey 7500 to 15000 establishments are surveyed annually. Our sample of the IAB JVS includes 59329 observations on recruitment cases from 2000-2013.

As a measure of the productivity annual GDPs of 16 German federal states are used in the estimations. The data is provided by the Federal Statistical Office of Germany includes unadjusted regional GDP at current prices in Euro.

\subsection{Empirical Approach}

To estimate the effect of GDP on the proportion of the referral hiring we use the two-step estimation procedure suggested by Solon et al. (1994). The estimation approach is used to deal with the Moulton (1986) problem. According to Moulton (1986) individuals in the same year have a component of variance in common, that can be entirely attributed neither to the individual characteristics, nor to the aggregate variables in the year. As a result the standard error of the aggregate variables is underestimated, because of the positive correlation of the error component across the individuals.

To get around with the problem on the first step $R E F_{j, i, t}$ is regressed on the control variables, state and time dummies. $R E F_{j, i, t}$ equals 1 , if the $j^{\text {th }}$ recruitment is done through referrals, at time $t$, and in the state $i . R E F_{j, i, t}$ takes value 0 , if the $j^{\text {th }}$ recruitment is done through formal channels, at time $t$, and in the state $i$. In case of using the SOEP data $j$ is the identifier for the individual, while in case of using the JVS data $j$ is the identifier for the firm. The first step of the estimation is characterized by the following regression equation:

$$
R E F_{j, i, t}=B_{0}+\mathbf{B X}+\sum \sum s_{i, t} D_{i, t}+\gamma_{j, i, t}
$$

where $\mathbf{B}$ is the vector of coefficients on the vector of exogenous variables $\mathbf{X} . D_{i, t}$ are the time and state dummies. $\gamma_{i, t}$ are the i.i.d. error terms.

When using SOEP data several exogenous variables are used on the first step of the estimations. Among them there are variables indicating the individuals' education ${ }^{1}$, age, gender and the nationality. In addition we include a categorical variable with four categories showing the size of the firm in which the $j^{\text {th }}$ individual is employed at time $t . F S I Z E_{j, i, t}$ is a categorical variable with four categories showing the size of the firm in which the $j^{\text {th }}$ individual is employed at time $t$. The four categories are: less than 20 employees, 20 to 200, 200 to 2000, and more than 2000 employees. Another categorical variable included indicates the industry of the firm where the individual is employed at time $t$. The variable has 9 categories: Agriculture, Energy, Mining, Manufacturing, Construction, Trade, Transport, Bank/Insurance, and Services. Yet another categorical variable included has 5 categories and indicates which kind of job change preceded the current employment of the individual. The categories of the exogenous variable are the following: first job, job after break, job with new employer, company taken over, changed job at the same firm. Finally, the Standard International Socio-Economic Index of Occupational

\footnotetext{
${ }^{1}$ As an exogenous variable measuring the individual's education we use the amount of education or training in years computed by the SOEP (for detailed description see Helberger (1988) and Schwarze et al. (1991). The corresponding variable ranges from 7 to 18 .
} 
Status developed by Ganzeboom et al. (1992) is included as a control for the occupational status. ISEI index reflects individual's socio-economic status based on information about the individual's income, education, and occupation. It takes values in the range between 16 and 90 .

When the JVS data is used on the first step, the control variables include age and gender of the last hired employee. Moreover, we control for the previous employment status of the employee. The corresponding categorical variable has 9 categories with information if previously the employee was unemployed, employed elsewhere, self-employed, in vocational training/further education, temporary worker at the establishment and etc. A categorical variable with 6 categories shows the size of the firm. The six categories are: less than 10 employees, 10 to 19, 20 to 49, 50 to 199, 200 to 499 and more than 499 employees. Additionally we control for the search duration of the firm using the variable indicating the search duration in days. Further, two binary choice variables are used the one indicating if there were impediments or external reasons during the past 12 months, which prevented the firm to fully use its opportunities, the second, indicating whether the firm searched for employees in vain during the past 12 months.

On the second step the time and state fixed effects $\hat{s_{i, t}}$ estimated on the first step are regressed on the GDP, the time and state dummies, and the interaction term between the state GDPs and state dummies. The interaction term is included in the regression equation to control for the regional difference of the effect of state GDP. Thus, the second step of the estimation is characterized by the following regression equation:

$$
\hat{s_{i, t}}=a_{i}+\beta_{1} G D P_{i, t}+\beta_{2 i} G D P_{i, t} \times a_{i}+\delta_{t}+\tau_{i, t}
$$

where $\delta_{t}$ is the time fixed effect, $a_{i}$ is the state fixed effect, and $\tau_{i, t}$ are the i.i.d. error terms. Thus, the sign of the sum $\beta_{1}+\beta_{2 i}$ determines the sign of the effect of state specific GDPs on the proportion of workers recruited through referrals at the states. The estimation results of the second step using the SOEP and JVS data are summarized in the Table 1 and the Table 2 respectively.

\subsection{Descriptive Statistics}

This section presents descriptive statistics of the variables used in the estimations. Table 1 reveals descriptive statistics of control variables from SOEP data. Means of continuous variables and percentages of observations in each category for categorical variables are displayed for the subgroups of individuals which found job through referrals, formal channels and total. SOEP data demonstrates that $32.43 \%$ of workers found their job through referrals. Further, those who found job through referrals are younger, less educated, and have lower ISEI socio-economic status than those workers which found their job through formal channels. Proportionally there are less females and more immigrants among those which found job through referrals. They are proportionally more frequently working in Agriculture, Mining, Manufacturing, Construction, Trade, and Transport, while less frequently working in Energy, Bank/Insurance, and Services. Finally, the last job change of those which found job through referrals is proportionally more often categorized as "First Job", "Job With New Employer", and less often as "Job After Break", "Company Taken Over" and "Change Job, Same Firm".

Table 2 presents descriptive statistics of control variables from JVS data. The data reveals 
that on average $32.72 \%$ of workers are recruited through referrals. Unlike SOEP data, JVS data shows that workers hired through referrals are older and proportionally more often they are females compared to workers hired through formal channels. But both datasets show that workers hired through referrals are working at smaller companies. Previous employment status of workers hired through referrals is proportionally more often categorized as "Employed elsewhere", "Self-employed", "Did not work (e.g. housewife)", and "Other", and less often as "Unemployed", "Temporary worker ate the establishment", and in vocational training/further education at the establishment or elsewhere. Search duration is shorter for the workers recruited through referrals. Further, firms which hired through referrals experienced more impediments or external reasons during the past 12 months, which prevented the firm to fully use its opportunities, and they searched for employees in vain less often during the past 12 months.

Table 1: Descriptive statistics of control variables.

\begin{tabular}{lccc}
\hline \hline & SOEP & & \\
\hline Variable & Referrals & Formal channels & Overall \\
\hline Education & 12.02 & 12.75 & 12.51 \\
Age & 33.85 & 34.39 & 34.21 \\
Gender & & & \\
Male & 46.02 & 44.63 & 45.08 \\
Female & 53.98 & 55.37 & 54.92 \\
Nationality & & & \\
Germans & $89.57 \%$ & $93.58 \%$ & $92.28 \%$ \\
Immigrants & $10.43 \%$ & $6.42 \%$ & $7.72 \%$ \\
Firm size & & & \\
LT 20 & $42.62 \%$ & $29.68 \%$ & $33.88 \%$ \\
GE 20 LT 200 & $29.40 \%$ & $29.66 \%$ & $29.58 \%$ \\
GE 200 LT 2000 & $14.43 \%$ & $19.11 \%$ & $17.59 \%$ \\
GE 2000 & $13.54 \%$ & $21.54 \%$ & $18.95 \%$ \\
Industry & & & \\
Agriculture & $1.74 \%$ & $1.51 \%$ & $1.58 \%$ \\
Energy & $0.52 \%$ & $1.02 \%$ & $0.86 \%$ \\
Mining & $0.16 \%$ & $0.12 \%$ & $0.14 \%$ \\
Manufacturing & $14.90 \%$ & $13.93 \%$ & $14.24 \%$ \\
Construction & $11.96 \%$ & $11.66 \%$ & $11.76 \%$ \\
Trade & $22.98 \%$ & $17.04 \%$ & $18.97 \%$ \\
Transport & $5.94 \%$ & $5.51 \%$ & $5.65 \%$ \\
Bank/Insurance & $2.24 \%$ & $3.86 \%$ & $3.34 \%$ \\
Services & $39.57 \%$ & $45.35 \%$ & $43.47 \%$ \\
Type of job change & & & \\
First Job & $12.77 \%$ & $11.10 \%$ & $11.64 \%$ \\
Job After Break & $24.06 \%$ & $26.55 \%$ & $25.74 \%$ \\
Job With New Employer & $60.43 \%$ & $46.91 \%$ & $51.30 \%$ \\
Company Taken Over & $0.89 \%$ & $3.80 \%$ & $2.86 \%$ \\
Changed Job, Same Firm & $1.85 \%$ & $11.64 \%$ & $8.47 \%$ \\
ISEI & 40.83 & 45.87 & 44.23 \\
\hline Observations & 6210 & 12938 & 19148 \\
& $32.43 \%$ & $67.57 \%$ & $100 \%$ \\
\hline \hline
\end{tabular}


Table 2: Descriptive statistics of control variables.

\begin{tabular}{|c|c|c|c|}
\hline \multicolumn{4}{|l|}{ 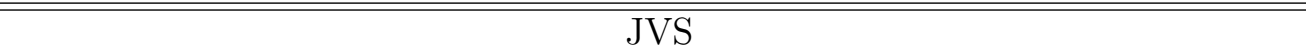 } \\
\hline Variable & Referrals & Formal & Overall \\
\hline Age* $^{*}$ & 36.14 & 34.88 & 35.29 \\
\hline \multicolumn{4}{|l|}{ Gender } \\
\hline Male & $41.00 \%$ & $47.25 \%$ & $45.20 \%$ \\
\hline Female & $59.00 \%$ & $52.75 \%$ & $54.80 \%$ \\
\hline Search duration $\dagger$ & 49.44 & 58.61 & 55.79 \\
\hline \multicolumn{4}{|l|}{ Firm size } \\
\hline LT 10 & $20.12 \%$ & $11.07 \%$ & $14.03 \%$ \\
\hline GE 10 LT 20 & $22.59 \%$ & $16.49 \%$ & $18.49 \%$ \\
\hline GE 20 LT 50 & $28.25 \%$ & $25.28 \%$ & $26.25 \%$ \\
\hline GE 50 LT 200 & $18.00 \%$ & $24.79 \%$ & $22.57 \%$ \\
\hline GE 200 LT 500 & $6.07 \%$ & $10.94 \%$ & $9.34 \%$ \\
\hline GE 500 & $4.98 \%$ & $11.43 \%$ & $9.32 \%$ \\
\hline \multicolumn{4}{|l|}{ Previous employment status $\dagger$} \\
\hline Unemployed & $34.44 \%$ & $36.97 \%$ & $36.14 \%$ \\
\hline Employed elsewhere & $45.37 \%$ & $42.08 \%$ & $43.16 \%$ \\
\hline Self-employed & $3.42 \%$ & $2.22 \%$ & $2.61 \%$ \\
\hline Vocational training/further education & $7.18 \%$ & $8.60 \%$ & $8.13 \%$ \\
\hline Did not work (e.g. housewife) & $3.71 \%$ & $2.37 \%$ & $2.81 \%$ \\
\hline Temporary worker at the establishment & $1.87 \%$ & $2.72 \%$ & $2.45 \%$ \\
\hline Vocational training at the establishment & $1.69 \%$ & $2.07 \%$ & $1.95 \%$ \\
\hline Vocational training/further education elsewhere & $2.10 \%$ & $2.85 \%$ & $2.60 \%$ \\
\hline Other & $0.22 \%$ & $0.11 \%$ & $0.15 \%$ \\
\hline \multicolumn{4}{|l|}{ Impediments or external reasons } \\
\hline Yes & $34.80 \%$ & $32.04 \%$ & $32.94 \%$ \\
\hline No & $62.53 \%$ & $65.25 \%$ & $64.36 \%$ \\
\hline Not specified & $2.68 \%$ & $2.71 \%$ & $2.70 \%$ \\
\hline \multicolumn{4}{|l|}{ Search in vain } \\
\hline Yes & $17.27 \%$ & $20.92 \%$ & $19.72 \%$ \\
\hline No & $76.82 \%$ & $73.79 \%$ & $74.78 \%$ \\
\hline Not specified & $5.91 \%$ & $5.30 \%$ & $5.50 \%$ \\
\hline \multirow[t]{2}{*}{ Observations } & 29556 & 60777 & 90333 \\
\hline & $32.72 \%$ & $67.28 \%$ & $100 \%$ \\
\hline
\end{tabular}

* Age is available for 88560 individuals.

$\ddagger$ Search duration is available for 72341 individuals.

$\dagger$ Survey methodology of previous employment status changed during the study period.From 2000 to 2003 respondent firms could choose options: Unemployed, Employed elsewhere, Vocational training/further education, Did not work (e.g. housewife), and Other. Starting from 2004 to 2007 Self-employed was added to the list. From 2008 to 2010 another option Temporary worker at the establishment was added. Throughout 2011 to 2013 the option Vocational training/further education was split to two different answers: Vocational training at the establishment and Vocational training/further education elsewhere. 90327 responses were recorded determining previous employment status in our dataset.

Before discussing estimation results, let us explore aggregated data for the study period from 2000 to 2014. Figure 1. presents aggregated descriptive statistics on the proportion of referral hiring and GDP of Germany over time.

The left $y$-axis of the two y-axis figure shows the proportion of referral hiring in percentage 


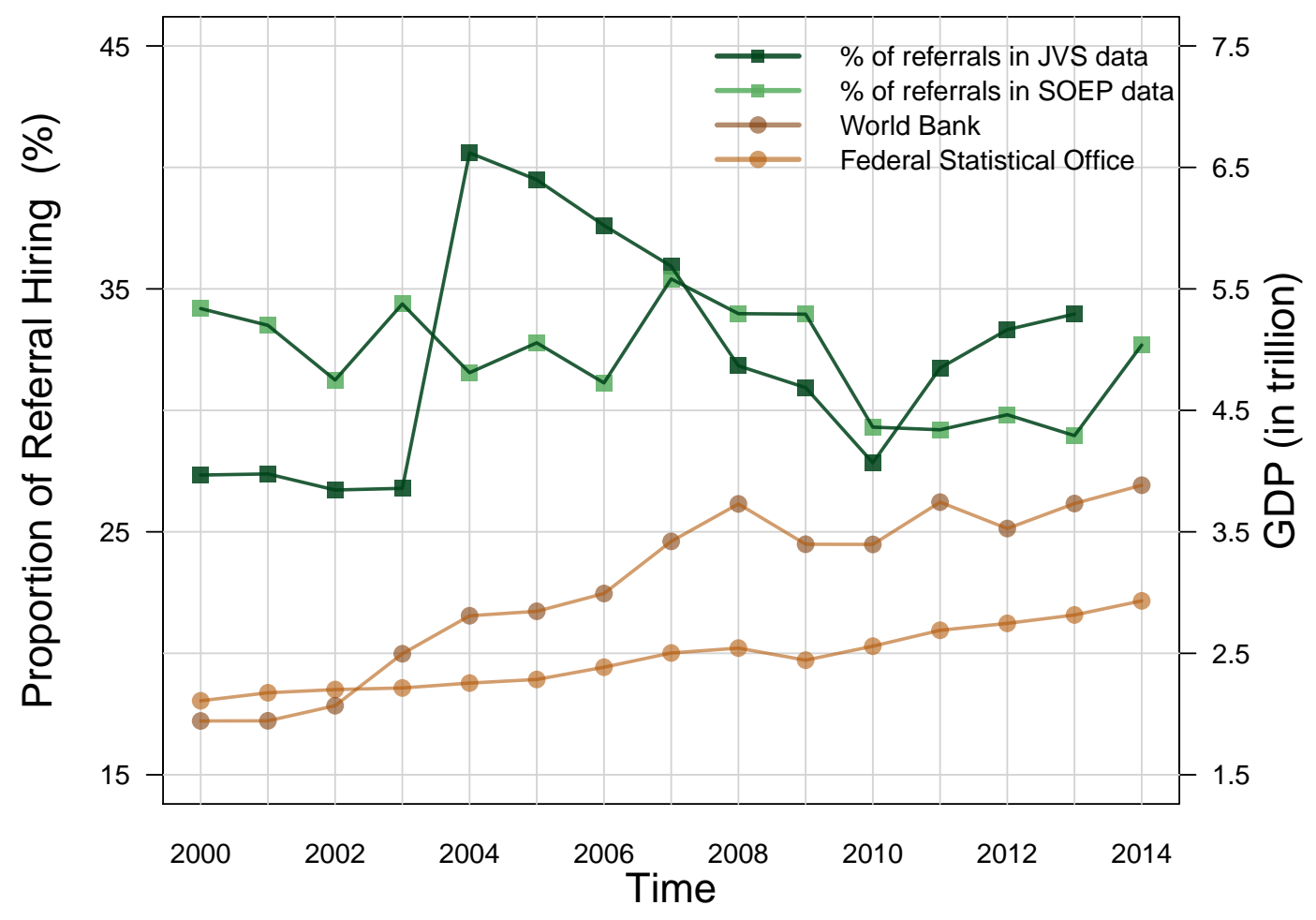

Figure 1: Proportion of referral hiring and GDP over time.

observed in SOEP and JVS datasets. The right y-axis shows the GDP of Germany measured in trillion. In the data from the World Bank GDP is measured at current prices in US dollars. The calendar and seasonally adjusted measure from the Federal Statistical Office of Germany is in euros. No clear pattern of correlation between the proportion of referral hiring and GDP can be determined in the figure. But we can see that proportion of referral hiring is decreasing in the period from 2008 to 2010, and the it starts recovering in both SOEP and JVS data. 


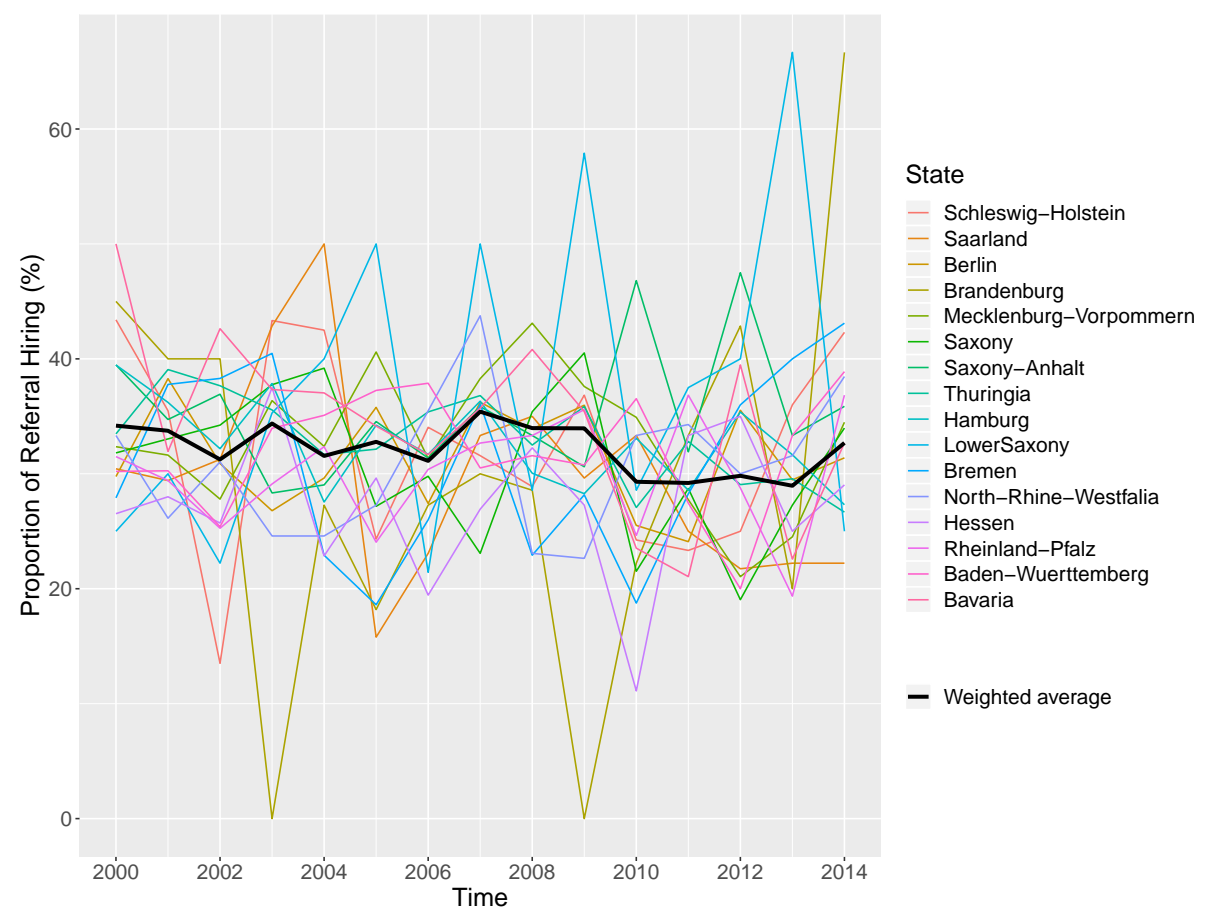

Figure 2: Regional proportions of referral hiring over time.

On the next step we observe the proportion of referral hiring in SOEP data by plotting the regional proportions, and average over time in Figure 2. The average is weighted by the number of observations from the region. We can observe large variability of proportions among the states, and different trajectories of regional proportions over time. These observations outline the importance of estimating regional proportions instead of proportion at country level.

Regional differences are also observed with respect to GDPs. Figure 3 depicts GDPs of German federal states over time. The calendar and seasonally adjusted data is provided by the Federal Statistical Office of Germany. Nominal values of state GDPs and their natural logarithms are presented in Figure 3 and Figure 4 respectively. Although regional GDPs follow similar pattern over time, there are large differences in their absolute values. This further motivates estimating regional proportions instead of proportion at country level. By estimating regional proportions, first, we are able to control for the state fixed effects and regional differences in the effect of state GDP. Second, larger data is exploited for statistical inference on the second step of the statistical approach, improving statistical significance of estimation results. 


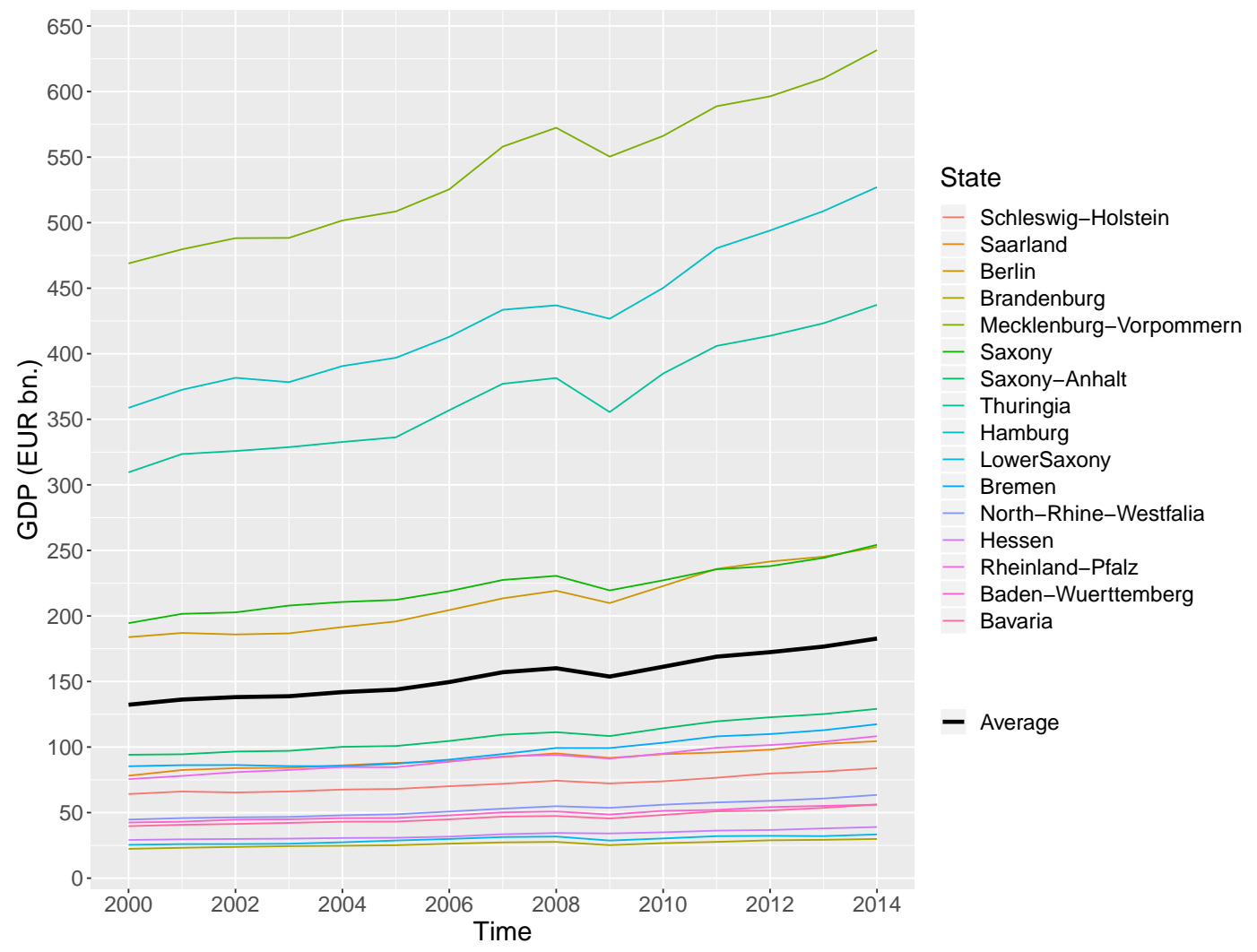

Figure 3: Nominal values of state GDPs over time.

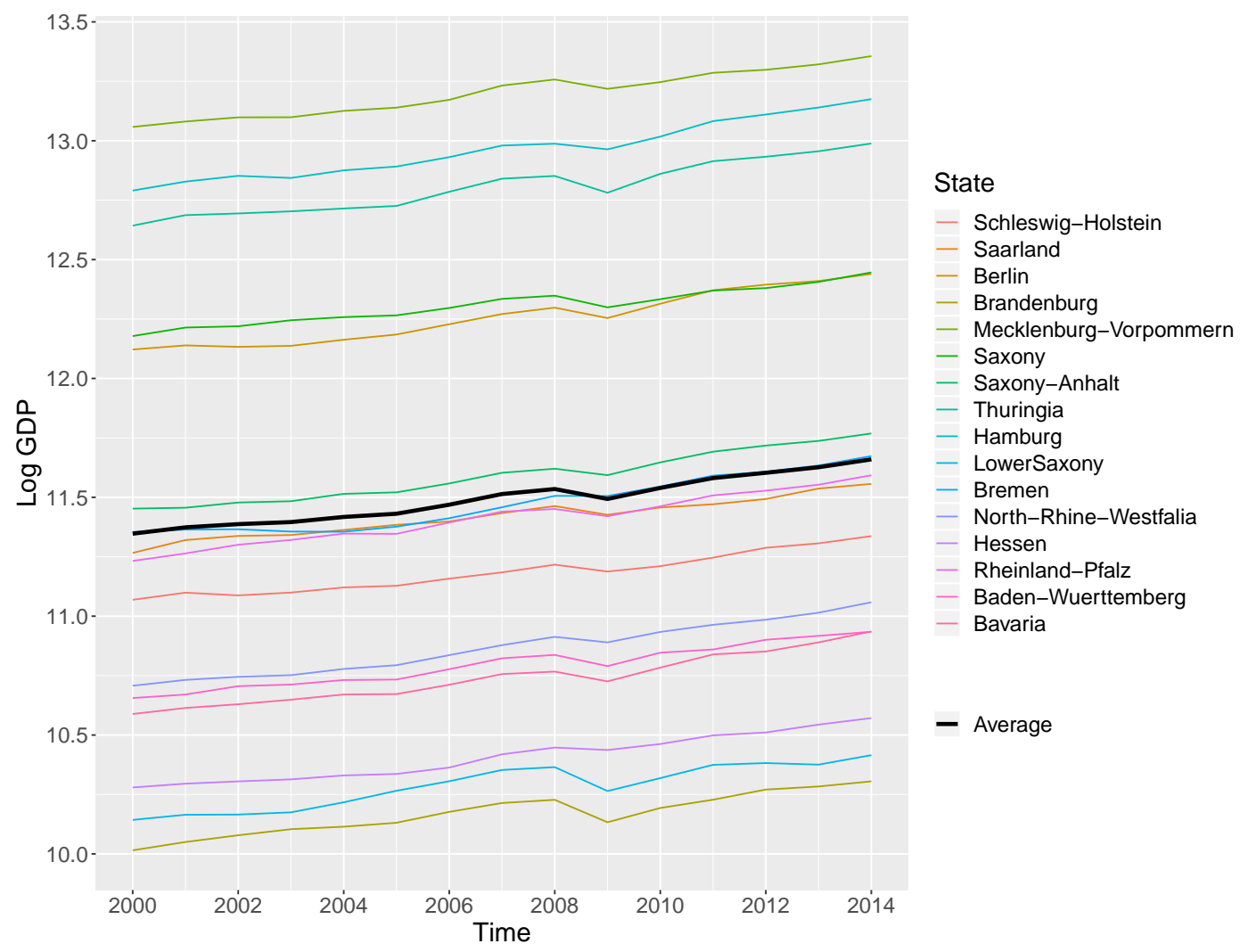

Figure 4: Natural logarithms of state GDPs over time. 


\subsection{Estimation Results}

The first column of the Table 3 presents the results of the estimations of the second step using state and time fixed effects and state specific effects of the natural logarithms of GDPs. According to the results the effect of GDP on the proportion of referrals used in recruitment $\beta_{1}+\beta_{2 i}$ is positive for all the states. Moreover, the coefficients of the state specific effects are statistically significantly different from the coefficient of the reference state Bavaria in case of all the states except Baden-Wuerttemberg. The significant differences highlight the importance of using interaction terms. Further, in the column 2 the time trend is used instead of the time fixed effects. In this case the effects are positive for all the states except Hamburg and Thuringia. The time trend turns to be negative and statistically significant, meaning that the proportion of referrals used in recruitment is decreasing over the time. It is important to note that compared to the first regression equation, the adjusted $\mathrm{R}$ squared is smaller in the second regression equation.

When the nominal levels of GDPs are used instead of their natural logarithms in the columns 3 and 4 , the results are similar. In case of using time fixed effects all the coefficients $\beta_{1}+\beta_{2 i}$ are again positive. The more, coefficients of the state specific effects are statistically significantly different from the coefficient of the reference state in case of all the states. While when using the time trend as an explanatory variable the state specific effects for four states become negative. And again the time trend is negative and statistically significant. Compared to the third regression equation, the adjusted $\mathrm{R}$ squared is smaller in the fourth regression equation indicating higher explanatory power of time fixed effects compared to the time trend. The empirical results obtained using the SOEP data suggest that the effect of GDP on the proportion of workers hired through referrals is positive.

When the time and state fixed effects $\hat{s_{i, t}}$ from the first step of estimations using the JVS data are used as a dependant variable the coefficients obtained are qualitatively similar. The column 1 in the Table 4 shows that the effects of the state specific natural logarithms of GDPs are positive in all the states except Bremen and Berlin. Furthermore, the coefficients are significantly different from the coefficient of Bavaria in all the states except North-Rhein-Westfalia and Saarland, again indicating that the interaction terms should be included into the regression equation. In the regression equation represented by the column 2 the time fixed are substituted with a time trend. The trend is negative and statistically significant. Additionally, one more state specific effect of $\log G D P$ in the Saxony becomes negative compared to the column 1. The adjusted $\mathrm{R}$ squared is lower for the regression equation of the column 2 compared to the one of the column 1.

In the columns 3 and 4 the nominal levels of GDPs are used instead of their natural logarithms as explanatory variables. When using time fixed effects in the regression equation all the coefficients $\beta_{1}+\beta_{2 i}$ are positive except those in Bremen and Berlin. While the coefficients of the state specific effects are significantly different from the coefficient of Bavaria in case of all the states except Saxony and Saxony-Anhalt. Whereas, in the column 4 the time fixed effects are substituted with the time trend, and negative coefficients are obtained for the half of the states. But in the latter case the adjusted $\mathrm{R}$ squared is much lower compared to the statistic in the column 3 .

To sum up, the effect of the measure of productivity on the proportion of workers hired 
Table 3: Estimation results of the second step using SOEP data

\begin{tabular}{|c|c|c|c|c|}
\hline & $\begin{array}{c}(1) \\
\text { T\&S FE }\left(s_{i, t}\right)\end{array}$ & $\begin{array}{c}(2) \\
\text { T\&S FE }\left(s_{i, t}\right)\end{array}$ & $\begin{array}{c}(3) \\
\text { T\&S FE }\left(s_{i, t}\right)\end{array}$ & $\begin{array}{c}(4) \\
\text { T\&S FE }\left(s_{i, t}\right)\end{array}$ \\
\hline Reference year: 2000 & \multicolumn{2}{|c|}{$\log G D P_{i, t} \times$ State } & \multicolumn{2}{|c|}{$G D P_{i, t} \times$ State } \\
\hline Reference state: Bavaria & $\begin{array}{c}0.512^{* * *} \\
(0.027)\end{array}$ & $\begin{array}{c}0.069^{* * *} \\
(0.018)\end{array}$ & $\begin{array}{c}0.00123^{* * *} \\
(0.00006)\end{array}$ & $\begin{array}{l}-0.00005 \\
(0.00004)\end{array}$ \\
\hline Schleswig-Holstein & $\begin{array}{c}0.912^{* * *} \\
(0.028)\end{array}$ & $\begin{array}{c}0.290^{* * *} \\
(0.029)\end{array}$ & $\begin{array}{c}0.01316^{* * *} \\
(0.00056)\end{array}$ & $\begin{array}{c}0.00238^{* * *} \\
(0.00044)\end{array}$ \\
\hline Hamburg & $\begin{array}{l}0.621^{* *} \\
(0.037)\end{array}$ & $\begin{array}{l}-0.022^{*} \\
(0.040)\end{array}$ & $\begin{array}{c}0.00718^{* * *} \\
(0.00052)\end{array}$ & $\begin{array}{c}-0.00177^{* * *} \\
(0.00046)\end{array}$ \\
\hline Lower Saxony & $\begin{array}{c}0.683^{* * *} \\
(0.013)\end{array}$ & $\begin{array}{c}0.189^{* * *} \\
(0.014)\end{array}$ & $\begin{array}{c}0.00332^{* * *} \\
(0.00009)\end{array}$ & $\begin{array}{c}0.00041^{* * *} \\
(0.00007)\end{array}$ \\
\hline Bremen & $\begin{array}{c}1.019^{* * *} \\
(0.045)\end{array}$ & $\begin{array}{c}0.487^{* * *} \\
(0.049)\end{array}$ & $\begin{array}{c}0.04251^{* * *} \\
(0.00210)\end{array}$ & $\begin{array}{c}0.01625^{* * *} \\
(0.00201)\end{array}$ \\
\hline North-Rhine-Westfalia & $\begin{array}{c}0.817^{* * *} \\
(0.013)\end{array}$ & $\begin{array}{c}0.300^{* * *} \\
(0.013)\end{array}$ & $\begin{array}{c}0.00155^{* * *} \\
(0.00002)\end{array}$ & $\begin{array}{c}0.00033^{* * *} \\
(0.00002)\end{array}$ \\
\hline Hessen & $\begin{array}{c}0.829^{* * *} \\
(0.022)\end{array}$ & $\begin{array}{c}0.179^{* * *} \\
(0.021)\end{array}$ & $\begin{array}{c}0.00391^{* * *} \\
(0.00014)\end{array}$ & $\begin{array}{l}0.00019^{*} \\
(0.00011)\end{array}$ \\
\hline Rheinland-Pfalz & $\begin{array}{c}0.793^{* * *} \\
(0.017)\end{array}$ & $\begin{array}{c}0.281^{* * *} \\
(0.018)\end{array}$ & $\begin{array}{c}0.00751^{* * *} \\
(0.00025)\end{array}$ & $\begin{array}{c}0.00162^{* * *} \\
(0.00019)\end{array}$ \\
\hline Baden-Wuerttemberg & $\begin{array}{c}0.534 \\
(0.012)\end{array}$ & $\begin{array}{c}0.049 \\
(0.013)\end{array}$ & $\begin{array}{c}0.00151^{* * *} \\
(0.00003)\end{array}$ & $\begin{array}{c}-0.00015^{* *} \\
(0.00003)\end{array}$ \\
\hline Saarland & $\begin{array}{c}0.866^{* * *} \\
(0.037)\end{array}$ & $\begin{array}{c}0.441^{* * *} \\
(0.041)\end{array}$ & $\begin{array}{c}0.02994^{* * *} \\
(0.00158)\end{array}$ & $\begin{array}{c}0.01114^{* * *} \\
(0.00150)\end{array}$ \\
\hline Berlin & $\begin{array}{c}0.882^{* * *} \\
(0.017)\end{array}$ & $\begin{array}{c}0.399^{* * *} \\
(0.019)\end{array}$ & $\begin{array}{c}0.00937^{* * *} \\
(0.00027)\end{array}$ & $\begin{array}{c}0.00323^{* * *} \\
(0.00021)\end{array}$ \\
\hline Brandenburg & $\begin{array}{c}0.847^{* * *} \\
(0.017)\end{array}$ & $\begin{array}{c}0.388^{* * *} \\
(0.019)\end{array}$ & $\begin{array}{c}0.01663^{* * *} \\
(0.00056)\end{array}$ & $\begin{array}{c}0.00555^{* * *} \\
(0.00042)\end{array}$ \\
\hline Mecklenburg-Vorpommern & $\begin{array}{c}0.809^{* * *} \\
(0.025)\end{array}$ & $\begin{array}{c}0.275^{* * *} \\
(0.027)\end{array}$ & $\begin{array}{c}0.02534^{* * *} \\
(0.00115)\end{array}$ & $\begin{array}{c}0.00502^{* * *} \\
(0.00093)\end{array}$ \\
\hline Saxony & $\begin{array}{c}0.775^{* * *} \\
(0.014)\end{array}$ & $\begin{array}{c}0.312^{* * *} \\
(0.016)\end{array}$ & $\begin{array}{c}0.00893^{* * *} \\
(0.00029)\end{array}$ & $\begin{array}{c}0.00236^{* * *} \\
(0.00021)\end{array}$ \\
\hline Saxony-Anhalt & $\begin{array}{c}0.832^{* * *} \\
(0.022)\end{array}$ & $\begin{array}{c}0.266^{* * *} \\
(0.023)\end{array}$ & $\begin{array}{c}0.01765^{* * *} \\
(0.00076)\end{array}$ & $\begin{array}{c}0.00293^{* * *} \\
(0.00056)\end{array}$ \\
\hline Thuringia & $\begin{array}{c}0.366^{* * *} \\
(0.018)\end{array}$ & $\begin{array}{c}-0.141^{* * *} \\
(0.020)\end{array}$ & $\begin{array}{c}0.00856^{* * *} \\
(0.00068)\end{array}$ & $\begin{array}{c}-0.00507^{* * *} \\
(0.00050)\end{array}$ \\
\hline Time trend & & $\begin{array}{c}-0.00577^{* * *} \\
(0.00043)\end{array}$ & & $\begin{array}{c}-0.00338^{* * *} \\
(0.00039)\end{array}$ \\
\hline Time FE & $\mathrm{v}$ & & $\mathrm{v}$ & \\
\hline State FE & $\mathrm{v}$ & $\mathrm{v}$ & $\mathrm{v}$ & $\mathrm{v}$ \\
\hline Constant & $\begin{array}{c}-6.602^{* * *} \\
(0.349)\end{array}$ & $\begin{array}{c}10.615^{* * *} \\
(0.660)\end{array}$ & $\begin{array}{c}-0.49679^{* * *} \\
(0.36948)\end{array}$ & $\begin{array}{c}6.73418^{* * *} \\
(0.76842)\end{array}$ \\
\hline Observations & 19148 & 19148 & 19148 & 19148 \\
\hline Adjusted $R^{2}$ & 0.2988 & 0.1273 & 0.3016 & 0.1247 \\
\hline
\end{tabular}

Standard errors in parentheses

${ }^{*} p<0.05,{ }^{* *} p<0.01,{ }^{* * *} p<0.001$ 
Table 4: Estimation results of the second step using JVS data

\begin{tabular}{|c|c|c|c|c|}
\hline & $\begin{array}{c}(1) \\
\text { T\&S FE }\left(s_{i, t}\right)\end{array}$ & $\begin{array}{c}(2) \\
\text { T\&S FE }\left(s_{i, t}\right)\end{array}$ & $\begin{array}{c}(3) \\
\text { T\&S FE }\left(s_{i, t}\right)\end{array}$ & $\begin{array}{c}(4) \\
\text { T\&S FE }\left(s_{i, t}\right)\end{array}$ \\
\hline Reference year: 2000 & \multicolumn{2}{|c|}{$\log G D P_{i, t} \times$ State } & \multicolumn{2}{|c|}{$G D P_{i, t} \times$ State } \\
\hline Reference state: Bavaria & $\begin{array}{c}0.147^{* * *} \\
(0.014)\end{array}$ & $\begin{array}{c}0.083^{* * *} \\
(0.012)\end{array}$ & $\begin{array}{c}0.00031^{* * *} \\
(0.00003)\end{array}$ & $\begin{array}{l}0.000002 \\
(0.00003)\end{array}$ \\
\hline Schleswig-Holstein & $\begin{array}{c}0.219^{* * *} \\
(0.018)\end{array}$ & $\begin{array}{c}0.109 \\
(0.024)\end{array}$ & $\begin{array}{c}0.00268^{* * *} \\
(0.00033)\end{array}$ & $\begin{array}{l}-0.00018 \\
(0.00036)\end{array}$ \\
\hline Hamburg & $\begin{array}{c}0.321^{* * *} \\
(0.021)\end{array}$ & $\begin{array}{c}0.260^{* * *} \\
(0.028)\end{array}$ & $\begin{array}{c}0.00327^{* * *} \\
(0.00029)\end{array}$ & $\begin{array}{c}0.00145^{* * *} \\
(0.00033)\end{array}$ \\
\hline Lower Saxony & $\begin{array}{c}0.659^{* * *} \\
(0.009)\end{array}$ & $\begin{array}{c}0.575^{* * *} \\
(0.012)\end{array}$ & $\begin{array}{c}0.00292^{* * *} \\
(0.00005)\end{array}$ & $\begin{array}{c}0.00218^{* * *} \\
(0.00006)\end{array}$ \\
\hline Bremen & $\begin{array}{c}-0.184^{* * *} \\
(0.030)\end{array}$ & $\begin{array}{c}-0.211^{* * *} \\
(0.041)\end{array}$ & $\begin{array}{c}-0.00785^{* * *} \\
(0.00132)\end{array}$ & $\begin{array}{c}-0.01226^{* * *} \\
(0.00164)\end{array}$ \\
\hline North-Rhine-Westfalia & $\begin{array}{c}0.159 \\
(0.009)\end{array}$ & $\begin{array}{l}0.090 \\
(0.011)\end{array}$ & $\begin{array}{c}0.00025^{* * *} \\
(0.00002)\end{array}$ & $\begin{array}{l}-0.00004 \\
(0.00002)\end{array}$ \\
\hline Hessen & $\begin{array}{l}0.185^{*} \\
(0.016)\end{array}$ & $\begin{array}{c}0.155^{* * *} \\
(0.019)\end{array}$ & $\begin{array}{c}0.00070^{* * *} \\
(0.00009)\end{array}$ & $\begin{array}{c}0.00006 \\
(0.00009)\end{array}$ \\
\hline Rheinland-Pfalz & $\begin{array}{c}0.359^{* * *} \\
(0.012)\end{array}$ & $\begin{array}{c}0.281^{* * *} \\
(0.017)\end{array}$ & $\begin{array}{c}0.00311^{* * *} \\
(0.00015)\end{array}$ & $\begin{array}{c}0.00167^{* * *} \\
(0.00016)\end{array}$ \\
\hline Baden-Wuerttemberg & $\begin{array}{c}0.114^{* * *} \\
(0.008)\end{array}$ & $\begin{array}{c}0.037^{* * *} \\
(0.011)\end{array}$ & $\begin{array}{l}0.00025^{*} \\
(0.00002)\end{array}$ & $\begin{array}{c}-0.00016^{* * *} \\
(0.00003)\end{array}$ \\
\hline Saarland & $\begin{array}{c}0.149 \\
(0.026)\end{array}$ & $\begin{array}{c}0.199^{* * *} \\
(0.036)\end{array}$ & $\begin{array}{c}0.00427^{* * *} \\
(0.00102)\end{array}$ & $\begin{array}{l}0.00317^{*} \\
(0.00127)\end{array}$ \\
\hline Berlin & $\begin{array}{c}-0.231^{* * *} \\
(0.009)\end{array}$ & $\begin{array}{c}-0.402^{* * *} \\
(0.013)\end{array}$ & $\begin{array}{c}-0.00248^{* * *} \\
(0.00013)\end{array}$ & $\begin{array}{c}-0.00487^{* * *} \\
(0.00013)\end{array}$ \\
\hline Brandenburg & $\begin{array}{c}0.087^{* * *} \\
(0.009)\end{array}$ & $\begin{array}{c}0.033^{* * *} \\
(0.012)\end{array}$ & $\begin{array}{c}0.00129^{* * *} \\
(0.00028)\end{array}$ & $\begin{array}{c}-0.00123^{* * *} \\
(0.00026)\end{array}$ \\
\hline Mecklenburg-Vorpommern & $\begin{array}{c}0.211^{* * *} \\
(0.011)\end{array}$ & $\begin{array}{c}0.112 \\
(0.015)\end{array}$ & $\begin{array}{c}0.00565^{* * *} \\
(0.00055)\end{array}$ & $\begin{array}{c}0.00009 \\
(0.00052)\end{array}$ \\
\hline Saxony & $\begin{array}{c}0.022^{* * *} \\
(0.007)\end{array}$ & $\begin{array}{c}-0.010^{* * *} \\
(0.010)\end{array}$ & $\begin{array}{c}0.00004 \\
(0.00015)\end{array}$ & $\begin{array}{c}-0.00122^{* * *} \\
(0.00013)\end{array}$ \\
\hline Saxony-Anhalt & $\begin{array}{c}0.049^{* * *} \\
(0.011)\end{array}$ & $\begin{array}{c}0.009^{* * *} \\
(0.014)\end{array}$ & $\begin{array}{c}0.00055 \\
(0.00038)\end{array}$ & $\begin{array}{c}-0.00213^{* * *} \\
(0.00034)\end{array}$ \\
\hline Thuringia & $\begin{array}{c}0.192^{* * *} \\
(0.009)\end{array}$ & $\begin{array}{c}0.147^{* * *} \\
(0.012)\end{array}$ & $\begin{array}{c}0.00372^{* * *} \\
(0.00035)\end{array}$ & $\begin{array}{c}0.00098^{* * *} \\
(0.00031)\end{array}$ \\
\hline Time trend & & $\begin{array}{l}-0.00054^{*} \\
(0.00027)\end{array}$ & & $\begin{array}{c}0.00172^{* * *} \\
(0.00026)\end{array}$ \\
\hline Time FE & $\mathrm{v}$ & & $\mathrm{V}$ & \\
\hline State FE & $\mathrm{v}$ & $\mathrm{v}$ & $\mathrm{v}$ & $\mathrm{v}$ \\
\hline Constant & $\begin{array}{c}-1.875^{* * *} \\
(0.182)\end{array}$ & $\begin{array}{c}0.062 \\
(0.425)\end{array}$ & $\begin{array}{c}-0.10841^{* * *} \\
(0.01201)\end{array}$ & $\begin{array}{c}-3.39681^{* * *} \\
(0.50644)\end{array}$ \\
\hline $\begin{array}{l}\text { Observations } \\
\text { Adiusted } R^{2}\end{array}$ & $\begin{array}{l}59329 \\
0.5751\end{array}$ & $\begin{array}{l}59329 \\
01935\end{array}$ & $\begin{array}{l}59329 \\
0.5723\end{array}$ & $\begin{array}{l}59329 \\
01898\end{array}$ \\
\hline
\end{tabular}

Standard errors in parentheses

${ }^{*} p<0.05,{ }^{* *} p<0.01,{ }^{* * *} p<0.001$ 
through referrals is positive in most of the states. The same is true in the estimations using both SOEP and JVS data. Moreover, in all the regression equations most of the coefficients of the interaction terms are significantly different from the reference state Bavaria. Which shows that the interaction terms should be included into the regression equation on the second step of the estimation. According to our empirical findings during the expansions when unemployment is relatively lower and there are relatively more vacancies, the proportion of referral hiring is higher. We propose a theoretical model to better understand the causes of the changes. In particular we explore the changes of the firms' advertisement intensity through the formal channels and the search effort of the workers through the formal channels over the business cycle.

\section{Model}

We develop a search and matching model with several search channels using the "Equilibrium Unemployment Theory" of Pissarides (2000). A continuum of risk neutral workers and firms live forever and discount future at a common discount rate r. Firms are homogeneous, and there is free entry of new vacancy with the flow cost $c$. In this setting the real productivity of the workers is $p$, and each worker has $h$ number of contacts. The workers can be matched to the firm through referrals or through formal channels.

\subsection{Matching function}

The matching functions for the two matching channels are different. Let $u$ be the unemployment rate of the workers, and $s$ be the search intensity through formal channels of the representative unemployed worker. su can be defined then as the efficiency units of searching workers. Furthermore, let $v$ be the vacancy rate, and $a$ be the level of job advertising of the representative hiring firm through formal channels. Thus, av can be defines as the efficiency units of job vacancies. We assume that the matching function through formal channels $m_{f}(s u, a v)$ has Cobb-Douglas form and write it as

$$
m_{f}(s u, a v)=\lambda_{0}(s u)^{1-\eta}(a v)^{\eta}
$$

Where $\lambda_{0}$ is the total factor productivity of the matching function, and $\eta$ is the elasticity with respect to the vacancy in the matching function. Note that $s$ and $a$ are the market averages. Given the search intensity of the representative worker and the job advertising of the representative firm the individual workers and firms choose their own search intensities and job advertising levels respectively. Let $s_{j}$ be the search intensity of the worker $j$. Unemployed workers move from unemployment into employment according to a Poisson process with rate $m_{f}(s u, a v) / s u$. The job finding rate of the worker $j$ in the formal market can be written as

$$
\lambda_{f j}=\frac{s_{j}}{s u} m_{f}(s u, a v)
$$

The job filling rate in the formal market of the firm is derived as follows. Let $a_{i}$ be the job advertising level of the firm $i$. A vacant job is filled according to a Poisson process with rate 
$m_{f}(s u, a v) / a v$. So the job filling rate of the firm $i$ in the formal market can be written as

$$
q_{f i}=\frac{a_{i}}{a v} m_{f}(s u, a v)
$$

In the symmetric Nash equilibrium all workers choose the same search intensity $s_{j}=s$, and all firms choose the same job advertising level $a_{i}=a$. Thus equations describing the job finding rate and the job filling rate for the representative worker and representative firm respectively can be written as follows:

$$
\begin{aligned}
\lambda_{f} & =\frac{m_{f}(s u, a v)}{u} \\
q_{f} & =\frac{m_{f}(s u, a v)}{v}
\end{aligned}
$$

Next, we explain the mechanism of referral hiring. Following Stupnytska and Zaharieva (2015), matching function in case of matching through referrals $m_{r}$ can be written as:

$$
m_{r}=v \alpha\left((1-u)\left(1-(1-u)^{h}\right)\right.
$$

Where $\alpha$ is the exogenous rate at which a vacancy arrives to a worker per unit time. (see Cahuc and Fontaine (2009).) The firm and the workers are matched through referrals as follows. The firm opens $v$ vacancies, and $v a$ vacancies arrive to an employed worker. Information about these vacancies is transmitted by the employed worker to a randomly chosen unemployed worker out of his or her $h$ contacts. $(1-u)^{h}$ is the probability that all the contacts of the employed worker are employed. So with probability $\left(1-(1-u)^{h}\right)$ the employed worker has at least one unemployed contact. Note, that unlike the model by Galeotti and Merlino (2003) the matching through referrals is modeled to be exogenous in the present paper. Job finding rate in case of finding job through referrals is $\lambda_{r}$ :

$$
\lambda_{r}=\frac{m_{r}}{u}
$$

Job filling rate in the informal market is $q_{r}$ :

$$
q_{r}=\frac{m_{r}}{v}
$$

The unemployment rate is given by the differences between the flows into and out of the unemployment. $1-u$ employed workers lose their job at rate $\delta$, so the flow into the unemployment is $\delta(1-u)$. While $u$ unemployed native workers find a job through formal channels at job finding rate $\lambda_{f}$. So the flow out of the unemployment through the formal channels is $\lambda_{f} u$. The $u$ unemployed workers may also find a job through referrals at job finding rate $\lambda_{r}$. So the flow out of the unemployment through referrals is $\lambda_{r} u$. Steady state equations for the unemployment rate can be described by the following equations:

$$
\dot{u}=\delta(1-u)-\lambda_{f} u-\lambda_{r} u=0
$$


At the steady state the flow into the unemployment equals to the flow out of the unemployment, so the equilibrium condition for unemployment can be written as:

$$
u=\frac{\delta}{\delta+\lambda_{f}+\lambda_{r}}
$$

\subsection{The choice of search intensity}

In the model unemployed workers choose the search intensity to maximize the present discounted value of being unemployed. We assume that the there is a cost associated with increasing the search intensity. The cost of $s_{j}$ units of search $\varphi_{j}$ is increasing at the margin and can be expressed by the following formula:

$$
\varphi_{j}\left(s_{j}\right)=C_{0} s_{j}^{2}
$$

Where $C_{0}$ is the variable cost of exerting one unit of search effort. We can think of $C_{0}$ as of a forgone leisure.

Let $w$ be the wage for all the employed workers, $W$ be the present discounted value of an employed worker, and $U$ be the present discounted value of an unemployed worker. At the exogenous rate $\delta$ employed workers lose their job and become unemployed, so the expected capital loss from losing a job for an employed worker is $\delta(W-U)$. Hence the equation for the present discounted value of an employed worker $W$ can be written as:

$$
r W=w-\delta(W-U) \quad \text { or } \quad W-U=\frac{w-r U}{(r+\delta)}
$$

The unemployed workers receive unemployment benefit $b$ while being unemployed. Additionally, supplying $s_{j}$ units of search intensity costs the worker $j, \varphi_{j}\left(s_{j}\right)$. At the job finding rate through referrals $\lambda_{r}$ the unemployed workers move from into employment through the referral hiring. So the expected capital gain of the unemployed worker from finding a job through referrals is $\lambda_{r}(W-U)$. While individual unemployed workers move into employment through formal channels at the job finding rate $\lambda_{f j}$. Then the expected capital gain of the unemployed worker $j$ from finding a job through formal channels is $\lambda_{f j}\left(W-U_{j}\right)$. Hence the equation for the present discounted value of unemployed worker $j$ will be

$$
r U_{j}=b-C_{0} s_{j}^{2}+\lambda_{f j}\left(W-U_{j}\right)+\lambda_{r}\left(W-U_{j}\right)
$$

The unemployed worker $j$ chooses the search intensity $s_{j}$ to maximize $U_{j}$ taking other variables as given. Thus, the equation for the optimal $s_{j}$ can be written as

$$
-2 C_{0} s_{j}+\frac{\partial \lambda_{f j}}{\partial s_{j}}\left(W-U_{j}\right)=0
$$

The equation (16) shows that the expected net gain $\left(W-U_{j}\right) \partial \lambda_{f j} / \partial s_{j}$ equals to the marginal cost of increasing the search intensity by one unit. In the symmetric equilibrium where the intensity of search of all unemployed workers is the same $s_{j}=s$, the partial derivative of job finding rate with respect to the search intensity $\partial \lambda_{f j} / \partial s_{j}$ can be derived using the equations (4) 
and (6)

$$
\frac{\partial \lambda_{f j}}{\partial s_{j}}=\frac{m_{f}(s u, a v)}{s u}=\frac{\lambda_{f}}{s}
$$

In the symmetric equilibrium the capital gain from finding a job $W-U$ can be derived using the equations (14) and (15).

$$
W-U=\frac{w-b+C_{0} s^{2}}{r+\delta+\lambda_{f}+\lambda_{r}}
$$

The derivation to the equation (18) is presented in Appendix I. After plugging in the expressions for the partial derivative of job finding rate with respect to the search intensity $\partial \lambda_{f j} / \partial s_{j}$ from (17) and the capital gain from finding a job $W-U$ from (18) into (16), the equation for the optimal search intensity at $s_{j}=s$ becomes:

$$
-2 C_{0} s+\frac{\lambda_{f}}{s} \frac{w-b+C_{0} s^{2}}{r+\delta+\lambda_{f}+\lambda_{r}}=0
$$

\subsection{The choice of job advertisement}

In the model the firms choose the job advertisement level to maximize the present discounted value of the firms' profit from an open vacancy. We assume that there is a cost associated with increasing the level of job advertisement through formal search channels. The cost of $a_{i}$ units of job advertisement through formal channels $c\left(a_{i}\right)$ :

$$
c\left(a_{i}\right)=k+C_{0} a_{i}^{2}
$$

where $\mathrm{k}$ is the fixed cost of recruitment through formal channels. Note that the variable cost of the job advertisement equals to the variable cost of exerting one unit of search effort. We can think of $k$ as a fixed cost of placing job advertisements in internet or newspapers, and $C_{0}$ as a wage paid to the recruiting staff.

Since the workers can be matched to the firm $i$ through two different channels, the expected return of an open vacancy to the firm $i$ consists of two parts. The product of the job filling rate through referrals and the expected net return of the job for the firm $i, q_{r}\left(J-V_{i}\right)$ is the expected return to the firm $i$ from hiring a worker through referrals. The product of the job filling rate through formal channels and the expected net return of the job for the firm $i, q_{f i}\left(J-V_{i}\right)$ is the expected return to the firm $i$ from hiring a worker through formal channels. Hence the equation for the asset value of an open vacancy for the firm $i$ can be written as:

$$
r V_{i}=-c\left(a_{i}\right)+q_{r}\left(J-V_{i}\right)+q_{f i}\left(J-V_{i}\right)
$$

The firm $i$ chooses the level of job advertisement $a_{i}$ to maximize the asset value of an open vacancy $V_{i}$. Thus, the equation for the optimal $a_{i}$ can be written as

$$
-2 C_{0} a_{i}+\frac{\partial q_{f i}}{\partial a_{i}}\left(J-V_{i}\right)=0
$$

where the $J$ is the asset value of a filled job. The equation (22) shows that the expected net profit of the firm $i,\left(J-V_{i}\right) \partial q_{f i} / \partial a_{i}$ equals to the marginal cost of increasing the job advertisement 
by one unit. In the symmetric equilibrium where the level of job advertisement of all firms is the same $a_{i}=a$, the partial derivative of job filling rate with respect to the job advertisement $\partial q_{f i} / \partial a_{i}$ can be derived using the equations (5) and (7)

$$
\frac{\partial q_{f i}}{\partial a_{i}}=\frac{m_{f}(s u, a v)}{a v}=\frac{q_{f}}{a}
$$

The equation for the present discounted value of the firm's profit from a filled job:

$$
r J=p-w-\delta\left(J-V_{i}\right) \quad \text { or } \quad J-V_{i}=\frac{p-w-r V_{i}}{r+\delta}
$$

where the firm $i$ benefits from the true productivity of workers $p$. According to the equation (24) the cost of a filled job consists of the wage $w$ and the net expected loss from job destruction.

Since the equilibrium is symmetric where the level of job advertisement of all firms is the same $a_{i}=a$, then $V_{i}=V$. Thus, under the Free Entry condition the equation for the asset value of an open vacancy can be rewritten as follows:

$$
r V=-k-C_{0} a^{2}+q_{r}(J-V)+q_{f}(J-V)=0
$$

And the corresponding equation for the optimal $a$ can be written as:

$$
-2 C_{0} a+\frac{q_{f}}{a}(J-V)=0
$$

The expression for the asset value of a filled job can be derived using the equation (25).

$$
J=\frac{k+C_{0} a^{2}}{q_{r}+q_{f}}
$$

After plugging in the expressions for the partial derivative of job filling rate with respect to the job advertisement $\partial q_{f i} / \partial a_{i}$ from (23) and the net profit from filling a job $J-V$ from (27), the equation for the optimal job advertisement effort becomes:

$$
-2 C_{0} a+\frac{q_{f}}{a}\left(\frac{k+C_{0} a^{2}}{q_{r}+q_{f}}\right)=0
$$

\subsection{Wage determination}

The wage rate is determined using the Nash bargaining rule. An individual firm and worker bargain of the wage taking $U$ and $V$ as given. Which means that an individual firm and worker do not influence the behavior in the rest of the labour market.

$$
(W-U)^{B}(J-V)^{1-B} \longrightarrow \max _{w}
$$

where $B$ is the bargaining power of the representative worker. If the negotiation is successful, then the worker is employed and gets the present discounted value of an employed worker $W$. While if the negotiation is not successful, the worker stays unemployed, so the outside of the worker is the present discounted value of an unemployed worker. Thus, the objective function of 
the representative worker is the capital gain from finding a job $W-U$. Similar, if the negotiation is successful, and the position is filled, the firm gets the asset value of a filled job $J$. But if the negotiation is not successful, and the position stays vacant, the firms gets the asset value of an open vacancy. So the objective function of the representative firm is the net return from hiring a worker $J-V$. We can substitute expressions for $W-U$ and $J-U$ from (14) and (24) respectively and rewrite the Nash bargaining solution.

$$
\left(\frac{w-r U}{r+\delta}\right)^{B}\left(\frac{p-w-r V}{r+\delta}\right)^{1-B} \longrightarrow \max _{w}
$$

When we apply the Free Entry condition $V=0$ and substitute the expression for $r U$ from (14) into the first order condition for the maximization problem we can write the wage equation.

$$
w=\frac{B p\left(r+\delta+\lambda_{f}+\lambda_{r}\right)+(1-B)\left(b-C_{0} s^{2}\right)(r+\delta)}{r+\delta+B \lambda_{f}+B \lambda_{r}}
$$

The derivation of the equation for the wage (31) is presented in Appendix II. We can substitute the RHS of the wage equation (31) into the value equation for the present discounted value of the firm's profit from a filled job (24) to get the job creation condition:

$$
(1-B)\left(p-b+C_{0} s^{2}\right)-B \frac{v}{u}\left(k+C_{0} a^{2}\right)-(r+\delta) \frac{k+C_{0} a^{2}}{q_{r}+q_{f}}=0
$$

The derivation of job creation condition (32) is presented in Appendix III.

Finally, the fraction of workers who found their job through referrals:

$$
f r=\frac{\lambda_{r}}{\lambda_{f}+\lambda_{r}}
$$

To sum up, in the model the equilibrium is characterized by the following five conditions: the equation for the optimal search intensity of unemployed workers, the equation for the optimal job advertisement effort of the firms, the equilibrium condition for unemployment, job creation condition, and fraction of workers who found their job through referrals. The model is used to numerically calculate some values of variables in the model and to find the changes of the key variables over the business cycle.

\section{Numerical example}

Let us first discuss the choice of the values of the exogenous variables and estimated parameters described in the Table 5. The real productivity of the workers $p$ is normalized to 1 . To estimate he matching function in formal market I use the monthly data from the Statistics Department of the Federal Employment Agency from June, 2012 to June, 2017 for 16 German federal states. Estimations show that the matching function demonstrates constant returns to scale. Further, I assume that the variables in the matching function cointegrate, and use Autoregressive distributive lag (ARDL) specification to estimate the parameters of the matching function. While comparing the results obtained using Pooled mean-group (PMG), Mean-group (MG) and fixed effect (FE) models, the Hausman test suggests that FE model is statistically prefered to be used 
in the estimations (see details in Appendix IV). According to the estimation results the elasticity with respect to the vacancy in the matching function $\eta$ equals 0.209 , and total factor productivity of the matching function $\lambda_{0}$ equals $e^{-0.652}=0.521$. But since the latter is obtained for the number of total matches, to get the number of matches through the formal search channels only, the total number of matches is multiplied by $1-f r$.

$$
\frac{m_{f}}{u}=\lambda_{f}=(1-f r) e^{-0.652} u^{1-0.209} v^{0.209}=(1-f r) \cdot 0.521 \cdot u^{0.791} v^{0.209}=\lambda_{0} \cdot u^{0.791} v^{0.209}
$$

Similar to the present study, Stops (2016) and Dengler et al. (2016) estimate the parameters of the matching function for the German labour market. Estimation results of Stops (2016) indicate that the average of the calculated values of $\lambda_{0}$ is around 0.75 , while, it is around 1.05 according to the estimation results of Dengler et al. (2016). Using German data Iftikhar and Zaharieva (2019) estimate $\lambda_{0}$ to be 0.5832 . So the estimate of this study is close to the lower bound of the values documented in the literature. Whereas, the estimate of the elasticity with respect to the unemployment $(1-\eta)$ is closer to the upper bound of the findings in the literature. Empirical studies estimated the elasticity with respect to unemployment to be from 0.5 to 0.7 . (Petrongolo and Pissarides (2001)) While, according to Stops (2016) $(1-\eta)$ ranges from 0.570 to 0.797 for different estimation equations. Iftikhar and Zaharieva (2019) estimate $1-\eta$ to be 0.4379 .

The fraction of workers who found job through referrals $f r$ is 0.2306 according to our estimates using IAB data, and 0.3025 when using GSOEP data. Alaverdyan (2018) observes the frequency of using referrals to find job for native Germans and immigrants and finds $27.53 \%$ of natives and $34.79 \%$ of immigrants find their job through referrals. Since we do not distinguish between natives and immigrants, 0.3 is chosen to be close to the average values in the literature and our estimates. Thus, $\lambda_{0}=(1-0.3) \cdot 0.521=0.3647$

The unit period of time being six months, the interest rate $r$ is chosen to be 0.01 . The values for the rest of exogenous variables are borrowed from the study by Stupnytska and Zaharieva (2015), since the author chooses the average values in the literature. The values of the exogenous variables is described in the Table 5 .

\begin{tabular}{c|c|l}
\hline Variable & Value & Explanation. Source. \\
\hline$p$ & 1 & Mean of the workers' true productivity. Normalization. \\
$\lambda_{0}$ & 0.3647 & Total factor productivity of the matching function. Own calculations \\
$\eta$ & 0.209 & $\begin{array}{l}\text { Elasticity with respect to vacancy in the matching function } \\
\text { Own calculations. }\end{array}$ \\
$h$ & 70 & Number of the contacts of workers. Stupnytska and Zaharieva (2015). \\
$b$ & 0.5 & Unemployment benefit. Average in the literature. \\
$c$ & 0.5 & Flow cost of the vacancy. Stupnytska and Zaharieva (2015). \\
$B$ & 0.72 & Bargaining power of the workers. Shimer (2005). \\
$r$ & 0.01 & Interest rate. Stupnytska and Zaharieva (2015). \\
$\delta$ & 0.2 & Job destruction rate. Stupnytska and Zaharieva (2015). \\
\hline
\end{tabular}

Table 5: Values of the exogenous variables

The theoretical model is calibrated with two steps. On the first step the values of exogenous variables, fraction of workers who found job through referrals, vacancy and unemployment rates 
are plugged into the five equilibrium conditions to solve for $\alpha, C_{0}, k, a$ and $s$. The values of these variables are used on the second step to numerically calculate the effect of productivity change on the key parameters of the labour market, such as wages, vacancy and unemployment rates, fraction of workers who found job through referrals, advertisement effort and search effort.

The unemployment rate is calculated according to the ILO guidelines using the SOEP data of the years from 2000 to 2014 . The vacancy rate is calculated using the monthly data from the Statistics Department of the Federal Employment Agency from January, 2000 to December, 2013. The ratio of vacancies and unemployment is 0.1048 in the data, so the vacancy rate is $0.1048 \cdot 0.0842=0.0088$. Calibration results of the first step are presented in Table 6 .

\begin{tabular}{c|c|l}
\hline Variable & Value & Explanation \\
\hline$f r$ & 0.3 & Fraction of workers who found job through referrals \\
$v$ & 0.0088 & Vacancy rate \\
$u$ & 0.0842 & Unemployment rate \\
\hline$\alpha$ & 6.8083 & Vacancy arrival rate \\
$C_{0}$ & 0.0057 & Fixed cost of the advertisement and search effort \\
$k$ & 1.4642 & Variable cost of the recruitment \\
$a$ & 11.7684 & Advertisement effort of the firms \\
$s$ & 5.7593 & Search effort of the workers \\
\hline
\end{tabular}

Table 6: Calibration results

One the second step the value of the productivity $p$ is changed from 0.55 to 1.5 , and the corresponding changes of the labour market parameters are presented in the Figure 5. According to the Figure 5. over the productivity increase the unemployment rate is decreasing, vacancy rate and the wages are increasing. These findings are inline with the predictions of the Pissarides (2000).

Further, when the productivity increases, the search effort of the workers increases, while the advertisement effort of the firms decreases. When the vacancy rate and wages increase, and the unemployment rate decreases, job search becomes more gainful for the workers. Thus, the increase of the search effort of the workers can be explained by these changes in the labour market. Intuitively, the advertisement of the vacancy should become more gainful for the firms because of the productivity increase. Whereas, the advertisement of the vacancy becomes less gainful for the firms because of the changes, since the wages increase, and there are less unemployed workers available per vacancy issued. The latter negative effect dominates the positive effect of the productivity increase, as a result the advertisement effort decreases. 

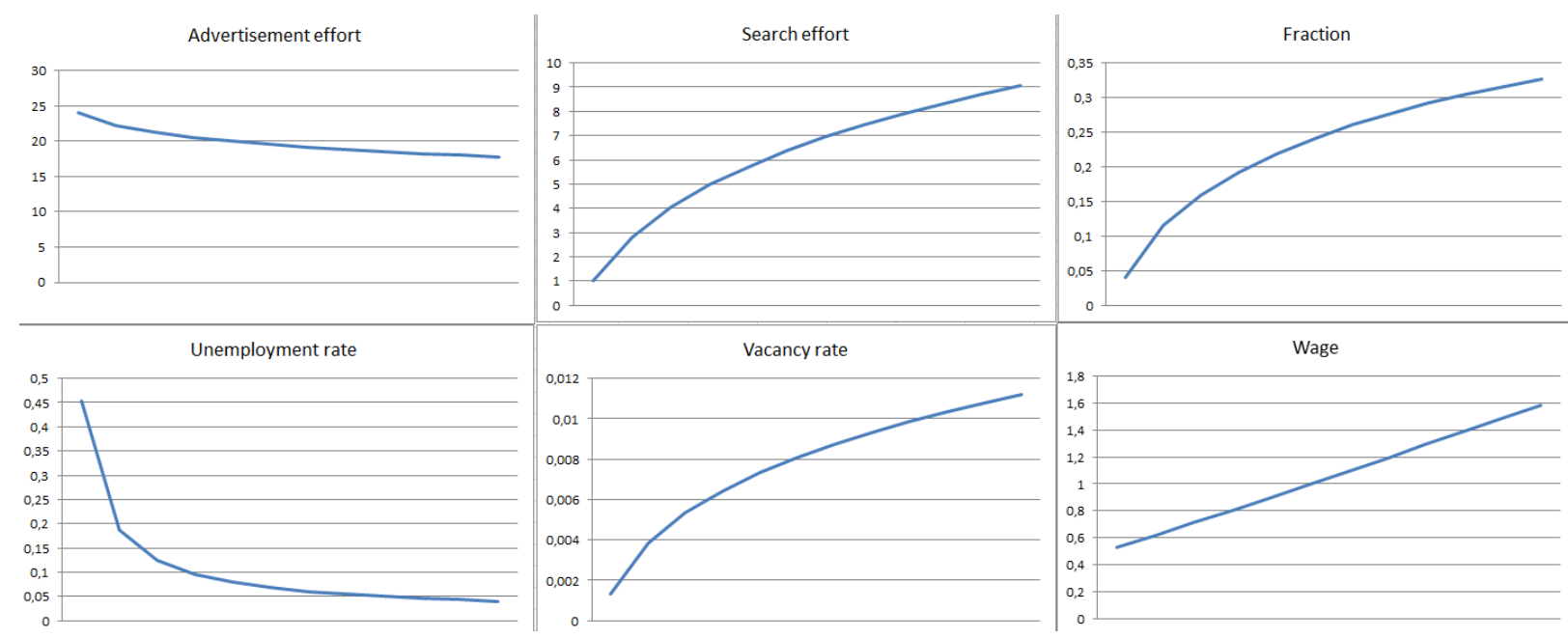

Figure 5: Calibration results on the change of the labour market parameters.

On the one hand, as the advertisement effort of the firms in the formal search channels decreases, intuitively, we would expect that the fraction of workers hired through referrals should increase. On the other hand, the search effort of the workers through formal search channels increases, as a result the fraction of workers hired through referrals would decrease. Thus the negative effect of the advertisement effort decrease on the fraction dominates the positive effect of the search effort increase. The calibration results confirm the empirical findings that the firm-side effect on the fraction dominates the effect from the worker's side .

\section{Conclusions}

Using the two-step estimation procedure we show that in the long run there is a positive correlation between the GDP and the proportion of workers hired through their social networks. Moreover, the results are similar when using both the SOEP and the JVS data for the empirical analysis.

In order to explain the effect of the productivity change on the search and matching channels of firms and workers, this paper presents a search and matching model with two search channels, where the workers choose their search intensity through formal channels, and the firms choose their optimal advertisement intensity.

Calibration results of the model show that during expansions vacancy rate and the wages are increasing, unemployment rate is decreasing. As a result, employment becomes more gainful for the workers, and they increase the job search intensity through formal channels. This reaction of the workers to the labour market conditions reduces the proportion of referral hiring.

When observing the effects of the labour market conditions of the advertisement effort of the firms, on the one hand, the productivity increases, so the advertisement of the vacancy through formal channels should become more gainful for the firms. On the other hand, during expansions there are less unemployed workers available per vacancy issued, and the wages are higher. Thus, the advertisement of the vacancy through formal channels is less gainful for the firms. Since the advertisement effort of the firms through formal channels decreases during expansion, the negative effect on the job adverti sement dominates. Which means that according to the behaviour 
of the firms during expansions the proportion of referral hiring should increase.

As the advertisement effort of the firms in the formal search channels decreases, intuitively, we would expect that the fraction of workers hired through referrals should increase. Whereas, the search effort of the workers through formal search channels increases, as a result the fraction of workers hired through referrals should decrease. The negative effect of the advertisement effort decrease on the fraction or the firm-side effect dominates the positive effect of the search effort increase of the workers or the workers-side effect. The calibration results, that the firm-side effect on the fraction dominates the effect from the worker's side, are inline with the empirical findings. 


\section{References}

Alaverdyan, S. (2018). Why do migrant workers rely more often on referrals?

Bentolila, S., C. Michelacci, and J. Suarez (2010). Social contacts and occupational choice. Economica 707(305), 20-45.

Cahuc, P. and F. Fontaine (2009). On the efficiency of job search with social networks. Journal of Public Economic Theory 11(3), 411-439.

Dengler, K., M. Stops, and B. Vicari (2016). Occupation-specific matching efficiency. Technical report, IAB-Discussion Paper.

Dustmann, C., A. Glitz, and U. Schönberg (2011). Referral-based job search networks.

Galenianos, M. (2013). Learning about match quality and the use of referrals. Review of Economic Dynamics 16(4), 668-690.

Galeotti, A. and L. P. Merlino (2003). Endogenous job contact networks. International Economic Review 55(4), 1201-1226.

Ganzeboom, H. B., P. M. De Graaf, and D. J. Treiman (1992). A standard international socioeconomic index of occupational status. Social science research 21(1), 1-56.

Granovetter, M. S. (1974). Getting a job : A study of contacts and careers. Cambridge, Mass,.

Helberger, C. (1988). Eine überprüfung der linearitätsannahme der humankapitaltheorie. Bildung, Beruf, Arbeitsmarkt 151, 170.

Iftikhar, Z. and A. Zaharieva (2019). General equilibrium effects of immigration in germany: Search and matching approach. Review of Economic Dynamics 31, 245-276.

Kugler, A. D. (2003). Employee referrals and efficiency wages. Labour Economics 10, 531-556.

Montgomery, J. D. (1991). Social networks and labor-market outcomes: Toward an economic analysis. The American Economic Review 81(5), 1408-1418.

Moulton, B. R. (1986). Random group effects and the precision of regression estimates. Journal of econometrics 32(3), 385-397.

Pesaran, M. H., Y. Shin, and R. P. Smith (1999). Pooled mean group estimation of dynamic heterogeneous panels. Journal of the American Statistical Association 94(446), 621-634.

Pesaran, M. H. and R. Smith (1995). Estimating long-run relationships from dynamic heterogeneous panels. Journal of econometrics 68(1), 79-113.

Petrongolo, B. and C. A. Pissarides (2001). Looking into the black box: A survey of the matching function. Journal of Economic literature 39(2), 390-431.

Pissarides, C. A. (2000). Equilibrium unemployment theory (2 ed.). Cambridge, Mass.: MIT Press. 
Pistaferri, L. (1999). Informal networks in the italian labor market. Giornale degli Economisti e Annali di Economia 58(3-4), 355-375.

Schwarze, J. et al. (1991). Ausbildung und einkommen von männern: Einkommensfunktionsschätzungen für die ehemalige ddr und die bundesrepublik deutschland. Mitteilungen aus der Arbeitsmarkt-und Berufsforschung 24(1), 63-69.

Shimer, R. (2004). Search intensity. Technical report, mimeo, University of Chicago.

Shimer, R. (2005). The cyclical behavior of equilibrium unemployment and vacancies. American economic review 95(1), 25-49.

Solon, G., R. Barsky, and J. A. Parker (1994). Measuring the cyclicality of real wages: how important is composition bias? The quarterly journal of economics 109(1), 1-25.

Stops, M. (2016). Revisiting german labour market reform effects - a panel data analysis for occupational labour markets. IZA Journal of European Labor Studies 5(1), 14.

Stupnytska, Y. and A. Zaharieva (2015). Explaining u-shape of the referral hiring pattern in a search model with heterogeneous workers. Journal of Economic Behavior and Orgainization 119, 211-233.

Zaharieva, A. (2018). On the optimal diversification of social networks in frictional labour markets with occupational mismatch. Labour Economics 50, 112-127. 


\section{Appendix}

\section{Appendix I. Derivation of the capital gain of finding a job:}

If we substitute the expression for the $W-U$ from the RHS of the equation (14) into the equation (15), then the equation for the present discounted value of being unemployed at $s_{j}=s$ can be written as

$$
r U=b-C_{0} s^{2}+\left(\lambda_{f}+\lambda_{r}\right)\left(\frac{w-r U}{(r+\delta)}\right)
$$

When we move the $r U$ from the RHS to the LHS of the equation (35) we get

$$
r U\left(1+\frac{\lambda_{f}+\lambda_{r}}{(r+\delta)}\right)=b-C_{0} s^{2}+\frac{w\left(\lambda_{f}+\lambda_{r}\right)}{(r+\delta)}
$$

To get the expression for the $r U$ the equation (36) can be rewritten as

$$
r U=\frac{\left(b-C_{0} s^{2}\right)(r+\delta)+w\left(\lambda_{f}+\lambda_{r}\right)}{r+\delta+\lambda_{f}+\lambda_{r}}
$$

When we substitute the expression for the $r U$ from the equation (37) into the equation (14) we get

$$
W-U=\frac{w\left(r+\delta+\lambda_{f}+\lambda_{r}\right)-\left(b-C_{0} s^{2}\right)(r+\delta)-w\left(\lambda_{f}+\lambda_{r}\right)}{(r+\delta)\left(r+\delta+\lambda_{f}+\lambda_{r}\right)}
$$

The equation (38) can be simplified to get the following expression for the capital gain of finding a job

$$
W-U=\frac{w-b+C_{0} s^{2}}{r+\delta+\lambda_{f}+\lambda_{r}}
$$

Appendix II. Derivation of the Wage equation: From (29) we know that the Nash bargaining solution can be expressed as:

$$
(W-U)^{B}(J-V)^{1-B} \longrightarrow \max _{w}
$$

The first order condition for the maximization problem we can be written as:

$$
\left(\frac{1}{r+\delta}\right) B(W-U)^{B-1}(J-V)^{1-B}-\left(\frac{1}{r+\delta}\right)(1-B)(W-U)^{B}(J-V)^{-B}=0
$$

We can substitute expressions for $W-U$ and $J-U$ from (14) and (24) respectively and rewrite the first order condition.

$$
\begin{aligned}
\left(\frac{1}{r+\delta}\right) B\left(\frac{w-r U}{r+\delta}\right)^{B-1}\left(\frac{p-w-r V}{r+\delta}\right)^{1-B} \\
-\left(\frac{1}{r+\delta}\right)(1-B)\left(\frac{w-r U}{r+\delta}\right)^{B}\left(\frac{p-w-r V}{r+\delta}\right)^{-B}=0
\end{aligned}
$$

If we devide both sides of the equation (42) by $(1 / r+\delta)((w-r U) /(r+\delta))^{B-1}((p-w-r V) /(r+\delta))^{-B}$ we will get:

$$
B(p-w-r V)-(1-B)(w-r U)=0
$$


From (43) the wage $w$ can be expressed as:

$$
w=B(p-r V)+(1-B) r U
$$

When we apply the Free Entry condition $V=0$, and substitute the expression for $r U$ from (37) into (44), we get the following wage equation:

$$
w=B(p-r V)+(1-B) \frac{\left(b-C_{0} s^{2}\right)(r+\delta)+w\left(\lambda_{f}+\lambda_{r}\right)}{r+\delta+\lambda_{f}+\lambda_{r}}
$$

The equation (45) can be simplified to get the following expression for the wage.

$$
w=\frac{B p\left(r+\delta+\lambda_{f}+\lambda_{r}\right)+(1-B)\left(b-C_{0} s^{2}\right)(r+\delta)}{r+\delta+B \lambda_{f}+B \lambda_{r}}
$$

\section{Appendix III. Derivation of the job creation condition:}

In the symmetric equilibrium under the Free Entry condition the equation (24) can be rewritten as:

$$
J=\frac{p-w}{r+\delta}
$$

Additionally, according to (27) the expression for the asset value of a filled job can be written as:

$$
J=\frac{k+C_{0} a^{2}}{q_{r}+q_{f}}
$$

When we substitute the expression for the wage from (46) into (47) we get:

$$
\begin{aligned}
J=\frac{p\left(r+\delta+B \lambda_{f}+B \lambda_{r}\right)-B p\left(r+\delta+\lambda_{f}+\lambda_{r}\right)-(1-B)\left(b-C_{0} s^{2}\right)(r+\delta)}{\left(r+\delta+B \lambda_{f}+B \lambda_{r}\right)(r+\delta)} & = \\
& =\frac{(1-B) p-(1-B)\left(b-C_{0} s^{2}\right)}{r+\delta+B \lambda_{f}+B \lambda_{r}}
\end{aligned}
$$

The RHSs of (48) and (49) equal each other:

$$
\frac{k+C_{0} a^{2}}{q_{r}+q_{f}}=\frac{(1-B) p-(1-B)\left(b-C_{0} s^{2}\right)}{r+\delta+B \lambda_{f}+B \lambda_{r}}
$$

The equation (50) can be rewritten as follows:

$$
\left(q_{r}+q_{f}\right)(1-B)\left(p-b+C_{0} s^{2}\right)-B\left(\lambda_{f}+\lambda_{r}\right)\left(k+C_{0} a^{2}\right)-\left(k+C_{0} a^{2}\right)(r+\delta)=0
$$

If we divide both sides of (51) by $q_{r}+q_{f}$ we get the following job creation condition:

$$
(1-B)\left(p-b+C_{0} s^{2}\right)-B \frac{v}{u}\left(k+C_{0} a^{2}\right)-(r+\delta) \frac{k+C_{0} a^{2}}{q_{r}+q_{f}}=0
$$

where

$$
\frac{\lambda_{f}+\lambda_{r}}{q_{r}+q_{f}}=\frac{\frac{m_{f}(s u, a v)}{u}+\frac{m_{r}}{u}}{\frac{m_{f}(s u, a v)}{v}+\frac{m_{r}}{v}}=\frac{v}{u}
$$




\section{Appendix IV. Estimation of the matching function in formal market:}

We follow the random matching approach and assume that matching function in formal market has the following Cobb-Douglass form:

$$
m_{f}(s u, a v)=\lambda_{0}(s u)^{\alpha}(a v)^{\beta}
$$

where $\alpha$ is the elasticity with respect to the unemployment in the matching function, and $\beta$ elasticity with respect to the vacancy rate in the matching function. We can linearize the equation by taking the logarithms.

$$
\log \left(m_{f}(s u, a v)\right)=\log \lambda_{0}+\alpha \log (s u)+\beta \log (a v)
$$

The parameters $\lambda_{0}, \alpha$ and $\beta$ can be estimated using the following estimation equation.

$$
\log m_{i, t}=C_{0}+B_{u} \log u_{i, t}+B_{v} \log v_{i, t}+\epsilon_{i, t}
$$

where $C_{0}=\log \lambda_{0}, B_{u}=\alpha$ and $B_{v}=\beta . m_{i, t}$ is the flow from unemployment to employment in the state $i$ at time period $t, u_{i, t}$ and $v_{i, t}$ are number of unemployed workers and vacancies in the state $i$ at time period $t$ respectively, and $\epsilon_{i, t}$ is the error term for the state $i$ and time period $t$. In the estimations we use the monthly data from the Statistics Department of the Federal Employment Agency from June, 2012 to June, 2017 for 16 German federal states. The results of OLS estimation of the equation (56) are presented in Table 7.

When we include time trend $t$ in the estimation equation we get the following equation.

$$
\log m_{i, t}=C_{0}+B_{u} \log u_{i, t}+B_{v} \log v_{i, t}+t+\epsilon_{i, t}
$$

The $t$ test suggests that the time trend should not be added to the regression equation (56). Next, we control for the state fixed effects in the equation (3). The equation can be rewritten as following:

$$
\log m_{i, t}=C_{i}+B_{u} \log u_{i, t}+B_{v} \log v_{i, t}+\epsilon_{i, t}
$$

where $C_{i}$ is the state specific intercept. Equation (58) with a time trend can be rewritten as following:

$$
\log m_{i, t}=C_{i}+B_{u} \log u_{i, t}+B_{v} \log v_{i, t}+t+\epsilon_{i, t}
$$

The $t$ test suggests that the time trend should be added to the regression equation (58). The estimation results of the four equations mentioned above are presented in Table 7 .

Further, Hadri test for unit roots shows that the null hypothesis that all panels are stationary is rejected, so at least some panels have unit root for $\log m_{i, t}, \log u_{i, t}$ and $\log v_{i, t}$. But the same test shows that the stationarity of the first time differences of the variables can not be rejected. Thus, the time series of the variables are integrated of order one and they are likely to be cointegrated. So, if I assume that the variables cointegrate, Pooled mean-group (PMG) model by Pesaran et al. (1999) can be applied. 
Table 7: Estimation results of OLS and FE regressions.

\begin{tabular}{lcccc}
\hline \hline Regression equation & $(56)$ & $(57)$ & $(58)$ & $(59)$ \\
Estimation model & OLS & OLS & FE & FE \\
Dependent variable & $\operatorname{logm}_{i, t}$ & $\operatorname{logm}_{i, t}$ & $\operatorname{logm}_{i, t}$ & $\operatorname{logm}_{i, t}$ \\
\hline $\log _{i, t}$ & $0.778^{* * *}$ & $0.776^{* * *}$ & $0.610^{* * *}$ & $0.599^{* * *}$ \\
& $(0.0145)$ & $(0.0165)$ & $(0.0993)$ & $(0.0988)$ \\
$\log _{i, t}$ & & & & \\
& $0.234^{* * *}$ & $0.236^{* * *}$ & $0.132^{* *}$ & -0.0436 \\
$t$ & $(0.0123)$ & $(0.0141)$ & $(0.0407)$ & $(0.0657)$ \\
& & & & \\
& & -0.0000948 & & $0.00177^{* * *}$ \\
Constant & & $(0.000325)$ & & $(0.000524)$ \\
& $-1.208^{* * *}$ & $-1.139^{* * *}$ & 1.794 & 2.520 \\
\hline Observations & $(0.0844)$ & $(0.2508)$ & $(1.519)$ & $(1.525)$ \\
$R^{2}$ & 976 & 976 & 976 & 976 \\
\hline \hline
\end{tabular}

Standard errors in parentheses: ${ }^{*} p<0.05,{ }^{* *} p<0.01,{ }^{* * *} p<0.001$

The long-run matching function is given by:

$$
\log m_{i, t}=C_{i}+B_{u i} \log u_{i, t}+B_{v i} \log v_{i, t}+v_{i, t}
$$

Autoregressive distributive lag (ARDL) specification corresponding to the equation (60):

$\log m_{i, t}=\lambda_{i} \log m_{i, t-1}+C_{i}+\delta_{10 i} \log u_{i, t}+\delta_{20 i} \log v_{i, t}+\delta_{11 i} \log u_{i, t-1}+\delta_{21 i} \log v_{i, t-1}+\epsilon_{i, t}$

If we add $-\log m_{i, t-1}$ on both sides of equation (61) and rearrange it we can get:

$$
\begin{aligned}
\Delta \log m_{i, t}=-\left(1-\lambda_{i}\right)\left(\log m_{i, t-1}-\frac{\delta_{10 i}+\delta_{11 i}}{1-\lambda_{i}}\right. & \left.\log u_{i, t}-\frac{\delta_{20 i}+\delta_{21 i}}{1-\lambda_{i}} \log v_{i, t}\right) \\
& -\delta_{11 i} \Delta \log u_{i, t}-\delta_{21 i} \Delta \log v_{i, t}+C_{i}+\epsilon_{i, t}
\end{aligned}
$$

or

$\Delta \log m_{i, t}=\phi_{i}\left(\log m_{i, t-1}-B_{u i} \log u_{i, t}-B_{v i} \log v_{i, t}\right)$

$$
-\delta_{11 i} \Delta \log u_{i, t}-\delta_{21 i} \Delta \log v_{i, t}+C_{i}+\epsilon_{i, t}
$$

Where the error-correcting speed of adjustment term $\phi_{i}=-\left(1-\lambda_{i}\right)$, and long-run relationships $B_{u i}=\frac{\delta_{10 i}+\delta_{11 i}}{1-\lambda_{i}}, B_{v i}=\frac{\delta_{20 i}+\delta_{21 i}}{1-\lambda_{i}}$. There is a long-run relationship between the variables when $\phi_{i}$ is significantly negative, meaning that variables show a return to a long-run equilibrium. While there is no long-run relationship between variables when $\phi_{i}=0$.

In the PMG model the long-run coefficients are constrained to be equal across groups, i.e. $B_{u i}=B_{u}$ and $B_{v i}=B_{v}$, but the short run coefficients and the error variances are allowed to differ 
across groups. Thus, during estimation of the PMG model we use the following parametrization.

$$
\begin{aligned}
\Delta \log m_{i, t}=\phi_{i}\left(\log m_{i, t-1}-B_{u} \log u_{i, t}-B_{v} \log v_{i, t}\right) & \\
& -\delta_{11 i} \Delta \log u_{i, t}-\delta_{21 i} \Delta \log v_{i, t}+C_{i}+\epsilon_{i, t}
\end{aligned}
$$

In the mean-group (MG) model developed by Pesaran and Smith (1995) the model is fitted for each group separately, so all the coefficients are allowed to vary across groups and the means of them are reported. The parametrization of the MG is the following.

$\Delta \log m_{i, t}=\phi_{i}\left(\log m_{i, t-1}-B_{u i} \log u_{i, t}-B_{v i} \log v_{i, t}\right)$

$$
-\delta_{11 i} \Delta \log u_{i, t}-\delta_{21 i} \Delta \log v_{i, t}+C_{i}+\epsilon_{i, t}
$$

Fixed-effects (FE) estimation approach constrains all the slope coefficients to be equal across groups, i.e. $B_{u i}=B_{u}, B_{v i}=B_{v}, \delta_{11 i}=\delta_{11}$, and $\delta_{21 i}=\delta_{21}$, and only the intercept and the error variances are allowed be different across groups.

$$
\begin{aligned}
\Delta \log m_{i, t}=\phi\left(\log m_{i, t-1}-B_{u} \log u_{i, t}-B_{v} \log v_{i, t}\right) & \\
& -\delta_{11} \Delta \log u_{i, t}-\delta_{21} \Delta \log v_{i, t}+C_{i}+\epsilon_{i, t}
\end{aligned}
$$

The estimation results of the PMG, MG, and FE models are presented in Table 6 .

The results in the Table 8 show that the error-correcting speed of adjustment term $\phi_{i}$ is negative and statistically significant, so the variables show a return to a long-run equilibrium. Also, for all three models the long-run coefficient of time variable is statistically insignificant. Thus, Hausman test was conducted to determine which of the models without time trend is statistically preferred, and the test shows that FE model is more preferable. Furthermore, the test of $H_{0}: B_{u}+B_{v}=1$ did not reject the null hypothesis of the constant return to scale in the FE model without time trend. So we can rewrite equation (54) so that it has constant returns to scale $(\mathrm{CRS})$ :

$$
m_{f}(s u, a v)=\lambda_{0}(s u)^{1-\eta}(a v)^{\eta}
$$

If we divide both sides of (67) by su we get:

$$
\frac{m_{f}(s u, a v)}{s u}=\lambda_{0} \frac{(a v)^{\eta}}{(s u)^{\eta}}
$$

Equation (68) can be linearized by taking the logarithms.

$$
\log m u=\log \lambda_{0}+\eta \log v u
$$

where $\log m u=\log \frac{m_{f}(s u, a v)}{s u}$ and $\log v u=\log \frac{a v}{s u}$.

The parameters $\log \lambda_{0}=C_{0}$ and $\eta=B$ can be estimated using the following estimation equation.

$$
\log m u_{i, t}=C_{0}+B \log v u_{i, t}+\epsilon_{i, t}
$$


Table 8: Estimation results of the PMG, MG, and FE models.

\begin{tabular}{|c|c|c|c|c|c|c|}
\hline Regression equation & $\overline{~(64)}$ & & 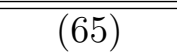 & & $(66)$ & \\
\hline Estimation model & PMG & PMG & MG & MG & $\mathrm{FE}$ & $\mathrm{FE}$ \\
\hline Dependent variable & $\Delta \log m_{i, t}$ & $\Delta \log m_{i, t}$ & $\Delta \log m_{i, t}$ & $\Delta \log m_{i, t}$ & $\Delta \log m_{i, t}$ & $\Delta \log m_{i, t}$ \\
\hline \multicolumn{7}{|l|}{ Long-run coef. } \\
\hline$B_{u}$ & $\begin{array}{c}0.730^{* * *} \\
(0.172)\end{array}$ & $\begin{array}{c}0.727^{* * *} \\
(0.171)\end{array}$ & $\begin{array}{l}0.372^{*} \\
(0.172)\end{array}$ & $\begin{array}{l}0.367^{*} \\
(0.154)\end{array}$ & $\begin{array}{l}0.788^{* * *} \\
(0.0895)\end{array}$ & $\begin{array}{l}0.786^{* * *} \\
(0.0884)\end{array}$ \\
\hline$B_{v}$ & $\begin{array}{c}0.168^{* *} \\
(0.0589)\end{array}$ & $\begin{array}{c}0.136 \\
(0.0842)\end{array}$ & $\begin{array}{l}-0.0159 \\
(0.0826)\end{array}$ & $\begin{array}{r}-0.00807 \\
(0.0797)\end{array}$ & $\begin{array}{c}0.145^{* *} \\
(0.0441)\end{array}$ & $\begin{array}{c}0.110 \\
(0.0578)\end{array}$ \\
\hline $\mathrm{t}$ & & $\begin{array}{c}0.000329 \\
(0.000631)\end{array}$ & & $\begin{array}{c}0.000244 \\
(0.000729)\end{array}$ & & $\begin{array}{c}0.000368 \\
(0.000453)\end{array}$ \\
\hline $\begin{array}{l}\text { Short-run coef. } \\
\phi\end{array}$ & $\begin{array}{c}-0.616^{* * *} \\
(0.0297)\end{array}$ & $\begin{array}{c}-0.618^{* * *} \\
(0.0298)\end{array}$ & $\begin{array}{c}-0.642^{* * *} \\
(0.0329)\end{array}$ & $\begin{array}{c}-0.643^{* * *} \\
(0.0329)\end{array}$ & $\begin{array}{c}-0.580^{* * *} \\
(0.0320)\end{array}$ & $\begin{array}{c}-0.581^{* * *} \\
(0.0321)\end{array}$ \\
\hline$\delta_{11}$ & $\begin{array}{c}-2.953^{* * *} \\
(0.227)\end{array}$ & $\begin{array}{c}-2.922^{* * *} \\
(0.224)\end{array}$ & $\begin{array}{c}-2.828^{* * *} \\
(0.245)\end{array}$ & $\begin{array}{c}-2.817^{* * *} \\
(0.262)\end{array}$ & $\begin{array}{c}-2.890^{* * *} \\
(0.251)\end{array}$ & $\begin{array}{c}-2.854^{* * *} \\
(0.265)\end{array}$ \\
\hline$\delta_{21}$ & $\begin{array}{c}-1.318^{* * *} \\
(0.118)\end{array}$ & $\begin{array}{c}-1.332^{* * *} \\
(0.119)\end{array}$ & $\begin{array}{c}-1.280^{* * *} \\
(0.148)\end{array}$ & $\begin{array}{c}-1.327^{* * *} \\
(0.168)\end{array}$ & $\begin{array}{c}-1.080^{* * *} \\
(0.141)\end{array}$ & $\begin{array}{c}-1.088^{* * *} \\
(0.145)\end{array}$ \\
\hline Constant & $\begin{array}{c}0.0149 \\
(0.0229) \\
\end{array}$ & $\begin{array}{l}0.097^{* * *} \\
(0.0273)\end{array}$ & $\begin{array}{c}3.478 \\
(1.908)\end{array}$ & $\begin{array}{l}3.649^{*} \\
(1.615)\end{array}$ & $\begin{array}{l}-0.247 \\
(0.829)\end{array}$ & $\begin{array}{r}-0.1717 \\
(0.829)\end{array}$ \\
\hline Observations & 960 & 960 & 960 & 960 & 960 & 960 \\
\hline
\end{tabular}

Standard errors in parentheses: ${ }^{*} p<0.05,{ }^{* *} p<0.01,{ }^{* * *} p<0.001$ 
When we include time trend $t$ in the estimation equation we get the following equation.

$$
\log m u_{i, t}=C_{0}+B \log v u_{i, t}+t+\epsilon_{i, t}
$$

If we control for the state fixed effects in the equation (71), the equation can be rewritten as following:

$$
\log m u_{i, t}=C_{i}+B \log v u_{i, t}+\epsilon_{i, t}
$$

where $C_{i}$ is again the state specific intercept. Equation (72) with a time trend can be rewritten as following:

$$
\log m u_{i, t}=C_{i}+B \log v u_{i, t}+t+\epsilon_{i, t}
$$

\begin{tabular}{|c|c|c|c|c|}
\hline Regression equation & $(70)$ & $(71)$ & $\overline{(72)}$ & $(73)$ \\
\hline Estimation model & OLS & OLS & $\mathrm{FE}$ & $\mathrm{FE}$ \\
\hline Dependent variable & $\log m u_{i, t}$ & $\log m u_{i, t}$ & $\log m u_{i, t}$ & $\log m u_{i, t}$ \\
\hline $\operatorname{logvu}_{i, t}$ & $\begin{array}{l}0.236^{* * *} \\
(0.0122)\end{array}$ & $\begin{array}{l}0.239^{* * *} \\
(0.0140)\end{array}$ & $\begin{array}{l}0.202^{* * *} \\
(0.0180)\end{array}$ & $\begin{array}{c}0.121^{* *} \\
(0.0386)\end{array}$ \\
\hline $\mathrm{t}$ & & $\begin{array}{l}-0.000165 \\
(0.000322)\end{array}$ & & $\begin{array}{c}0.00116^{*} \\
(0.000486)\end{array}$ \\
\hline Constant & $\begin{array}{c}-1.066^{* * *} \\
(0.0217)\end{array}$ & $\begin{array}{c}-0.951^{* * *} \\
(0.2251)\end{array}$ & $\begin{array}{c}-1.125^{* * *} \\
(0.0314)\end{array}$ & $\begin{array}{r}-2.030^{* * *} \\
(0.3808)\end{array}$ \\
\hline Observations & 976 & 976 & 976 & 976 \\
\hline$R^{2}$ & 0.2769 & 0.2771 & 0.2769 & 0.2495 \\
\hline
\end{tabular}

The estimation results of the four equations mentioned above are presented in Table 9. Next, we

Table 9: Estimation results of OLS and FE regressions with CRS matching function.

conduct a Hadri test for unit root and find that the null hypothesis that all panels are stationary is rejected, so at least some panels have unit root for $\log m u_{i, t}$, and $\log v u_{i, t}$. But the same test shows that the stationarity of the first time differences of the variables can not be rejected. Thus, the time series of the variables are integrated of order one and they are likely to be cointegrated. If I assume that the variables cointegrate, Pooled mean-group (PMG) model can be applied. The long-run matching function is given by:

$$
\log m u_{i, t}=C_{i}+B \log v u_{i, t}+v_{i, t}
$$

Autoregressive distributive lag (ARDL) specification corresponding to the equation (74):

$$
\log m u_{i, t}=\lambda_{i} \log m u_{i, t-1}+C_{i}+\delta_{1 i} \log v u_{i, t}+\delta_{2 i} \log v u_{i, t-1}+\epsilon_{i, t}
$$

If we add $-\log m u_{i, t-1}$ on both sides of equation (75) and rearrange it we can get:

$$
\Delta \log m u_{i, t}=-\left(1-\lambda_{i}\right)\left(\log m u_{i, t-1}-\frac{\delta_{1 i}+\delta_{2 i}}{1-\lambda_{i}} \log v u_{i, t}\right)-\delta_{2 i} \Delta \log v u_{i, t}+C_{i}+\epsilon_{i, t}
$$


$\Delta \log m u_{i, t} \quad=\quad \phi_{i}\left(\log m u_{i, t-1}-B_{i} \log v u_{i, t}\right)-\delta_{2 i} \Delta \log v u_{i, t}+C_{i}+\epsilon_{i, t}$

Where $\phi_{i}=-\left(1-\lambda_{i}\right), B_{i}=\frac{\delta_{1 i}+\delta_{2 i}}{1-\lambda_{i}}$.

In the PMG model the long-run coefficient is constrained to be equal across groups $B_{i}=B$, but the short run coefficient and the error variances are allowed to differ across groups. Thus, during estimation of the PMG model we use the following parametrization.

$\Delta \log m u_{i, t} \quad=\quad \phi_{i}\left(\log m u_{i, t-1}-B \log v u_{i, t}\right)-\delta_{2 i} \Delta \log v_{i, t}+C_{i}+\epsilon_{i, t}$

In the mean-group (MG) model the model is fitted for each group separately, so all the coefficients are allowed to vary across groups. The parametrization of the MG is the following.

$$
\Delta \log m u_{i, t} \quad=\quad \phi_{i}\left(\log m u_{i, t-1}-B_{i} \log v u_{i, t}\right)-\delta_{2 i} \Delta \log v_{i, t}+C_{i}+\epsilon_{i, t}
$$

Fixed-effects (FE) estimation approach constrains all the slope coefficients to be equal across groups, i.e. $B_{i}=B$, and $\delta_{2 i}=\delta_{2}$, and only the intercept and the error variances are allowed be different across groups.

$\Delta \log m u_{i, t} \quad=\quad \phi\left(\log m u_{i, t-1}-B \log v u_{i, t}\right)-\delta_{2} \Delta \log v_{i, t}+C_{i}+\epsilon_{i, t}$

The estimation results of the PMG, MG, and FE models with CRS matching function are presented in Table 10.

Table 10: Estimation results of the PMG, MG, and FE models with CRS matching function.

\begin{tabular}{lcccccc}
\hline \hline Regression equation & $(78)$ & & $(79)$ & & $(80)$ & \\
Estimation model & $\mathrm{PMG}$ & $\mathrm{PMG}$ & $\mathrm{MG}$ & $\mathrm{MG}$ & $\mathrm{FE}$ & $\mathrm{FE}$ \\
Dependent variable & $\Delta \log m u_{i, t}$ & $\Delta \log m u_{i, t}$ & $\Delta \log m u_{i, t}$ & $\Delta \log m u_{i, t}$ & $\Delta \log m u_{i, t}$ & $\Delta \log m u_{i, t}$ \\
\hline $\begin{array}{l}\text { Long-run coef. } \\
\mathrm{B}\end{array}$ & $0.230^{* * *}$ & $0.202^{* * *}$ & $0.241^{* * *}$ & $0.228^{* * *}$ & $0.209^{* * *}$ & $0.165^{* * *}$ \\
& $(0.0291)$ & $(0.0530)$ & $(0.0322)$ & $(0.0467)$ & $(0.0181)$ & $(0.0302)$ \\
$\mathrm{t}$ & & 0.000391 & & 0.000338 & & 0.000643 \\
& & $(0.000604)$ & & $(0.000813)$ & & $(0.000549)$ \\
\hline Short-run coef. & & & & & & \\
$\phi$ & $-0.626^{* * *}$ & $-0.627^{* * *}$ & $-0.640^{* * *}$ & $-0.644^{* * *}$ & $-0.591^{* * *}$ & $-0.594^{* * *}$ \\
& $(0.0315)$ & $(0.0313)$ & $(0.0325)$ & $(0.0324)$ & $(0.0313)$ & $(0.0312)$ \\
$\delta_{2 i}$ & $-0.565^{* * *}$ & $-0.588^{* * *}$ & $-0.564^{* * *}$ & $-0.608^{* * *}$ & $-0.518^{* * *}$ & $-0.551^{* * *}$ \\
& $(0.0852)$ & $(0.0826)$ & $(0.0984)$ & $(0.120)$ & $(0.0768)$ & $(0.0987)$ \\
Constant & $-0.666^{* * *}$ & $-0.859^{* * *}$ & $-0.667^{* * *}$ & $-0.862^{*}$ & $-0.652^{* * *}$ & $-0.951^{* * *}$ \\
& $(0.0378)$ & $(0.0460)$ & $(0.0534)$ & $(0.3534)$ & $(0.0351)$ & $(0.2373)$ \\
\hline Observations & 960 & 960 & 960 & 960 & 960 & 960 \\
\hline \hline
\end{tabular}

Standard errors in parentheses: ${ }^{*} p<0.05,{ }^{* *} p<0.01,{ }^{* * *} p<0.001$

The results in the Table 10 show that the error-correcting speed of adjustment term $\phi_{i}$ is negative and statistically significant. This means that the variables show a return to a long-run 
equilibrium. Moreover, for all three models the long-run coefficient of time variable is statistically insignificant. To compare the models we used the models without time trend. Hausman test was conducted to determine which of the models is statistically preferred, and the test shows that FE model is more preferable. So, we use the coefficients of the FE model without time trend and with CRS matching function (79) to find the parameters needed for numerical calculations. 